\title{
Modeling, design, and experimental test of a zero-sequence current electromagnetic suppressor
}

\author{
Stefani Carolline Leal Freitas ${ }^{1}$ (D) | Luis Carlos Origa de Oliveira ${ }^{2}$ | \\ Priscila da Silva Oliveira ${ }^{1}$ | Bruno Exposto ${ }^{3}$ | José Gabriel Oliveira Pinto ${ }^{3}$ | \\ João Luiz Afonso ${ }^{3}$
}

\begin{abstract}
${ }^{1}$ Federal University of Tocantins, Campus de Palmas, 77001-090 Palmas, TO, Brazil

${ }^{2}$ Faculty of Electrical Engineering, State University of São Paulo, Ilha Solteira, SP, Brazil

${ }^{3}$ Centro ALGORITMI-University of Minho, Campus de Azurém, 4800-058 Guimarães, Portugal
\end{abstract}

\section{Correspondence}

Stefani Carolline Leal de Freitas, Federal University of Tocantins. Quadra 109 Norte, Avenida NS-15, ALCNO-14, Plano Diretor Nortel77001-090I.Palmas/TO, Brazil.

Email: stefaniclf@uft.edu.br

Peer Review

The peer review history for this article is available at https://publons.com/publon/ 10.1002/2050-7038.12222.

\section{Funding information}

CAPES-Coordination for the Improvement of Higher Education Personnel; CNPq - National Council for Scientific and Technological Development

\begin{abstract}
Summary
This paper presents the experimental investigation of an electromagnetic suppressor to minimize the circulation of zero-sequence currents in three-phase four-wire distribution systems. The proposed zero-sequence current electromagnetic suppressor (ZSS) integrates two distinct electromagnetic devices, namely a zero-sequence filter (ZSF) and a zero-sequence blocker (ZSB), connected in parallel and in series between the source and the load, respectively. In this paper are presented the theoretical modeling and analysis of each device, the mathematical concepts of harmonic compensation, and the procedures for the design and determination of the constructive details. The experimental results of the combined operation of the devices that integrate the ZSS demonstrate the feasibility of the proposed arrangement, by minimizing the flow of the zero-sequence harmonic currents in the source side, enabling a significant reduction of the current in the neutral conductor, and also by improving the system power factor.
\end{abstract}

\section{KEYWORDS}

electromagnetic suppressor, harmonics, passive filter power factor, zero-sequence currents

\begin{abstract}
Symbols and Abbreviations
Symbols: $L_{S f}$, filter self-inductances of superior coils; $L_{I f}$, filter self-inductances of inferior coils; $L_{f}$, filter inductance; $M_{f}$, mutual inductances between the coils of the same column; $M$, mutual inductances between coils of distinct columns; $\lambda_{f}$, coupling factor between the superior and inferior coils of the same column of the filter; $V_{1}^{h}$, positive voltage component; $V_{2}^{h}$, negative voltage component; $V_{0}^{h}$, zero-sequence voltage component; $L_{b}$, selfinductances of each coil of the blocker; $M_{b}$, mutual inductances of the different phases coils of the blocker; $\lambda_{b}$, mutual inductances of the blocker; $L_{Z S F}$, zero-sequence inductances of the ZSF; $L_{Z S B}$, zero-sequence inductances of the ZSB; $\xi_{f}$, conformity factor of the ZSF; $\xi_{b}$, conformity factor of the ZSB; $L_{R}, L_{S}, L_{T}$, characteristics inductances of phases R, S, and T; $I_{Z S}{ }_{-N L}$, zero-sequence current produced by the load; $I_{Z S F}$, current that flows through the ZSF; $L_{Z S}{ }_{g}$, zero-sequence equivalent inductance of the electrical power grid; $I_{Z S}{ }^{-} g$, current at source

Abbreviations: ZSS, zero-sequence electromagnetic suppressor; ZSB, zero-sequence blocker; ZSF, zero-sequence filter; $\mathrm{THD}_{\mathrm{V}}$, total harmonic distortion of the voltage; $\mathrm{THD}_{\mathrm{I}}$, total current distortion; $\mathrm{PF}$, power factor
\end{abstract}




\section{1 | INTRODUCTION}

In three-phase power grids, most of the loads are constituted by nonlinear devices, such as electronic variable speed drives, computers, LED lamps, printers, battery chargers, etc. Due to the nonlinear characteristics, these loads are often the cause of problems related to the power quality, which can result into high economic losses. In general, due to the continuous technologic innovation, the use of these loads is progressively increasing, since the benefits of using them are superior to the harmful effects caused. From this perspective, the harmonic currents generated by residential consumers are added to those generated by industrial and commercial facilities. ${ }^{1-6}$ This fact significantly decreases the power quality, resulting in serious consequences for all consumers and to the electric power distribution systems.

Under these conditions, power grids that supply loads with nonlinear characteristics usually have high currents flowing through the neutral conductor. ${ }^{7-14}$ Specific investigations reveal that the currents that circulate through the neutral conductor are predominantly characterized by zero-sequence harmonic currents, also called triplen harmonics (ie, $3^{\text {rd }}, 9^{\text {th }}, 15^{\text {th }}, \ldots$ ). Sometimes, these harmonic currents reach values higher than the fundamental component. ${ }^{5-10}$ In this situation, some problems are frequently detected, especially the overload of the neutral conductor, overheating of distribution transformers, reduction of the power factor in the power grid, and even interferences in communication systems. ${ }^{13-17}$

In the last years, different techniques, active and passive, have been applied aiming at the elimination or reduction of the zero-sequence harmonic currents in four-wire power systems. ${ }^{10-18}$ The use of electromagnetic devices has shown to be a promising alternative for the reduction of harmonic components, namely the triplen harmonics, which have a strong zero-sequence concentration. ${ }^{19-21}$ Electromagnetic devices are robust and practically immune to resonance problems ${ }^{20,21}$ and, when used in passive or even hybrid arrangements, represent an interesting alternative considering the technical and economic perspectives.

The zero-sequence electromagnetic suppressor (ZSS) is a passive arrangement composed of two distinct devices, a zero-sequence blocker (ZSB), and a zero-sequence filter (ZSF). These devices provide high and low impedance paths, resulting in the blocking and deviation of the triplen harmonics currents circulation. ${ }^{18}$ Connected in parallel between a source and a load, the ZSF acts as a low-impedance for the zero-sequence components. Its operation is related to a specific form of zig-zag connection between its six coils that compose the electromagnetic device. ${ }^{18-20}$

The ZSB acts as a high impedance for the zero-sequence components, connected in series with the power source. ${ }^{17,21}$ It is designed using three magnetically coupled coils, implemented in the central column of an EI laminated magnetic core.

This paper presents a complete study of a ZSS and is organized as follows: Section 2 presents the mathematical models of the ZSF and ZSB; Section 3 discusses the physical concepts of the harmonic compensation performed by the arrangement of the passive filters; Section 4 presents the ZSS prototype implementation details; in Section 5 the experimental results of the ZSS operation in different operating conditions are presented; finally, Section 6 presents the main conclusions of the study.

\section{2 | MATHEMATICAL MODEL OF THE ELECTROMAGNETIC SUPPRESSOR}

The following topics present the mathematical models and the functionalities of the ZSF and ZSB that constitutes the ZSS, as well as, the benefits and effectiveness of the conjunct operation of these devices in the mitigation the zerosequence harmonic currents generated by nonlinear loads.

\section{3 | ZERO-SEQUENCE FILTER (ZSF)}

The ZSF is composed by six coils. In this electromagnetic arrangement, two windings are juxtaposed on the same column to obtain a coupling with minimum dispersions, Figure 1A, providing a maximization of its functionality, which is obtained with a unitary coupling coefficient, Figure 1B.

In Figure 2 are represented the self and mutual inductances resulting from the ZSF electromagnetic arrangement. Assuming that: the self-inductances of superior $\left(L_{S f}\right)$ and inferior $\left(L_{I f}\right)$ coils are identical $\left(L_{S f}=L_{I f}=L_{f}\right)$; the mutual inductances between the coils of the same column $\left(M_{f}\right)$ are identical; and that the mutual inductances between coils of distinct columns $(M)$ are identical; it can be obtained the equations of positive (1), negative (2), and zero-sequence (3) voltage components. ${ }^{14}$ 


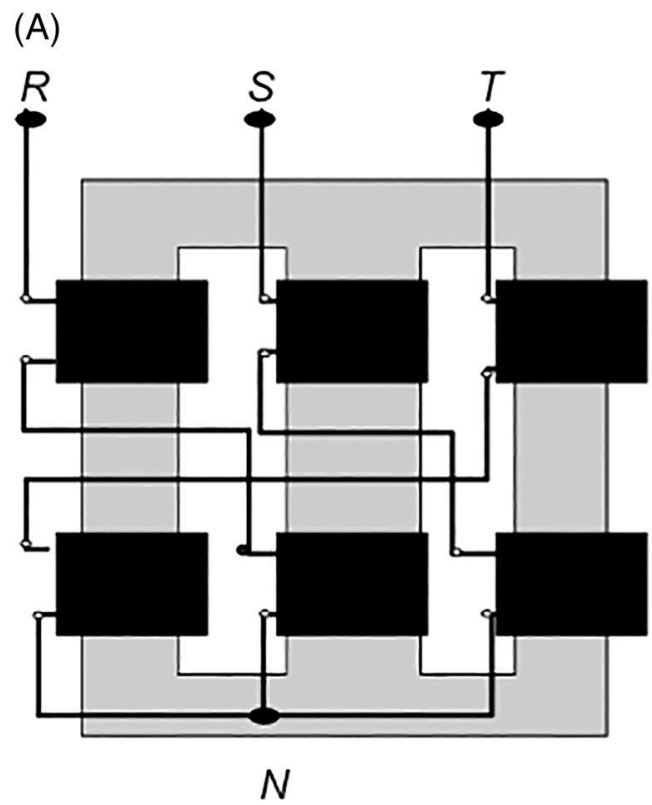

(B)

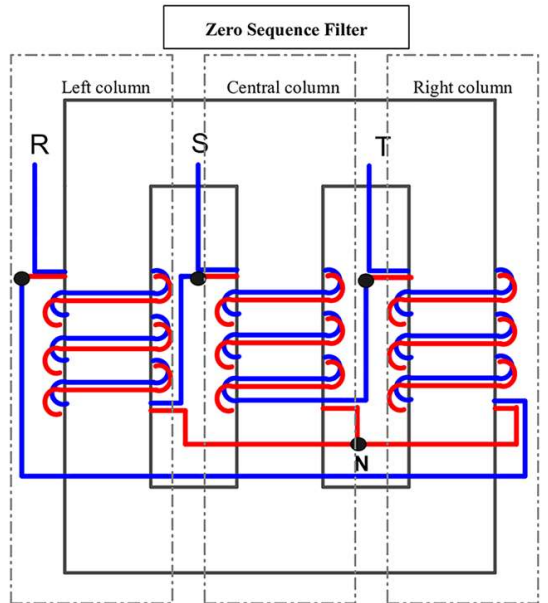

FIGURE 1 Representation of the ZSF electromagnetic arrangement: A, zig-Zag interconnection; B, details of the windings and interconnection

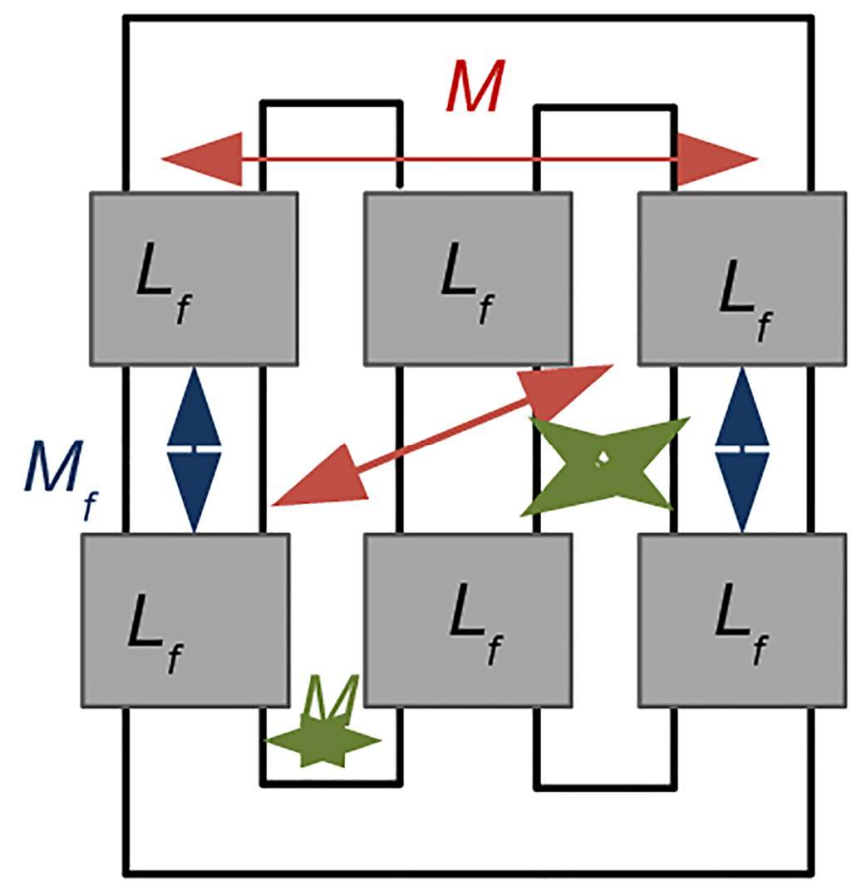

FIGURE 2 Representation of the ZSF winding coils self and mutual inductances

$$
\begin{gathered}
V_{1}^{h}=j \omega h\left[2 L_{f}+M_{f}+3 M\right] I_{1}^{h} \\
V_{2}^{h}=j \omega h\left[2 L_{f}+M_{f}+3 M\right] I_{2}^{h} \\
V_{0}^{h}=j \omega h\left[L_{f}-M_{f}\right] I_{0}^{h}
\end{gathered}
$$


From Equation (3), it is observed that, as the value of the mutual inductance between the coils of the same column, $M_{f}$, approaches to the self-inductance value of the coils, $L_{f}$, the zero-sequence equivalent inductance tends to a minimum value. The relationship between these inductances is expressed in Equation (4).

$$
M_{f}=\lambda_{f} \sqrt{L_{f} L_{f}}
$$

where $\lambda_{f}$, is the coupling factor between the superior and inferior coils of the same column of the ZSF.

Considering the coupling factor between the coils of a same column of the three-phase magnetic core, the equation system obtained in Equations (1), (2), and (3) can be represented by the decoupled sequential circuits shown in Figure 3.

\section{I ZERO-SEQUENCE BLOCKER (ZSB)}

The ZSB arrangement is formed by three coils arranged on the same column of a magnetic core as shown in Figure 4A. The mathematical model for the ZSB is developed based on the voltage and current ratios of mutually coupled coils,
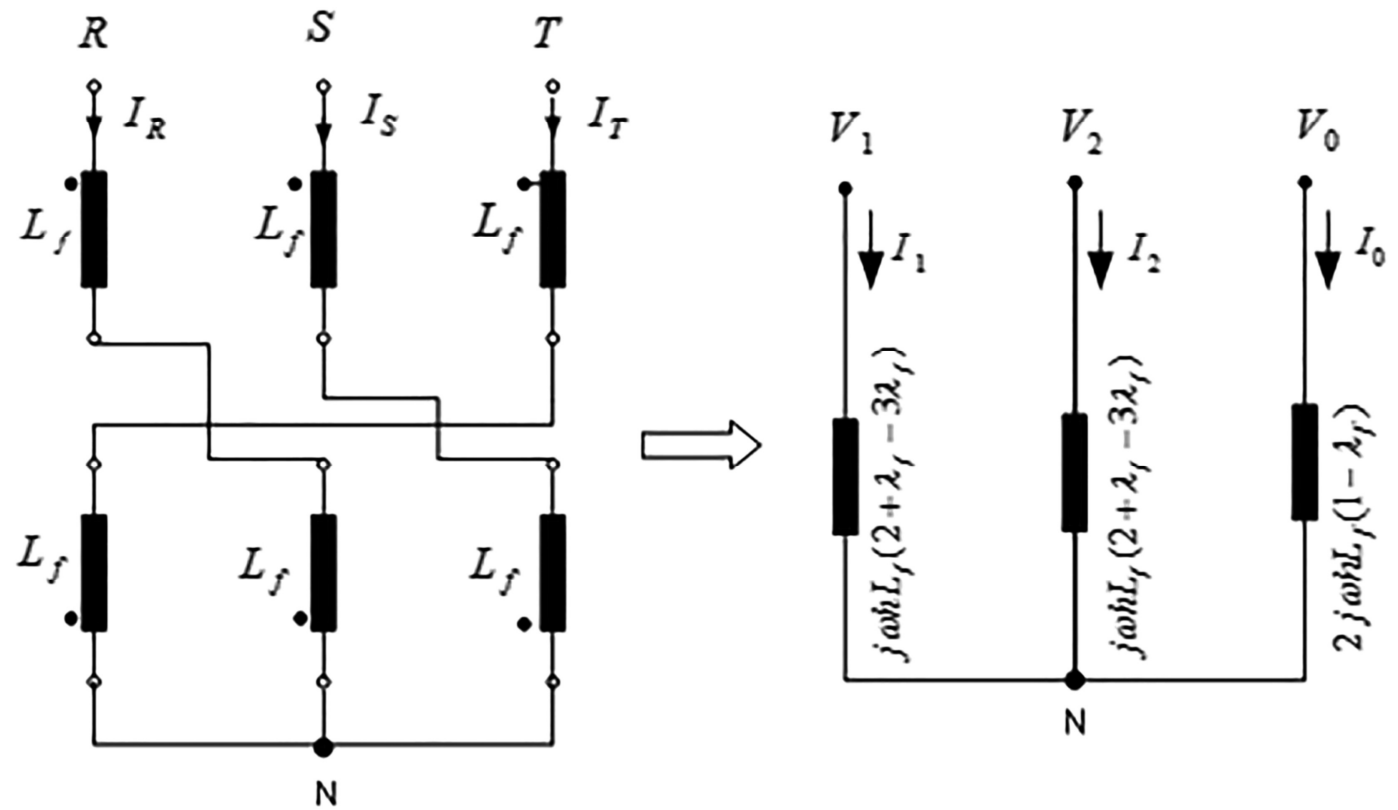

FIGURE 3 Decoupled sequential circuits of the ZSF

(A)

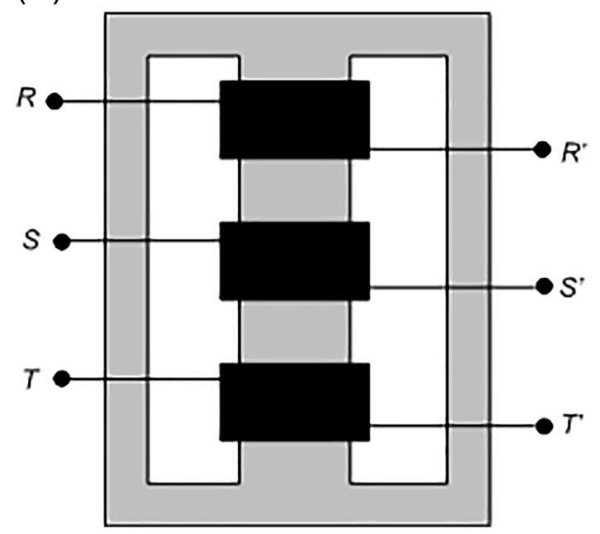

(B)

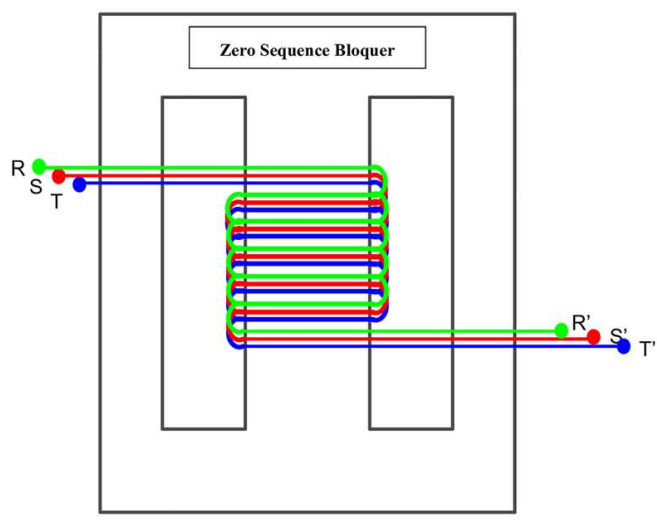

FIGURE 4 Representation of the ZSB electromagnetic arrangement: A, disposition of the coils; B, details of the windings 
supplied by a three-phase system. ${ }^{22}$ The coils are juxtaposed (Figure 4B) in order to provide a coupling with minimum dispersions, which ensures the maximization of its functionality, obtained by a unitary coupling coefficient.

Once the electromagnetic arrangement for the coils has been made, some considerations can be adopted, based on the similarity of the windings and the geometric and constructive aspects of the magnetic core. These simplifications ensure, from the analysis point of view, that the behavior of the zero-sequence components of the voltages and currents be investigated in an isolated way.
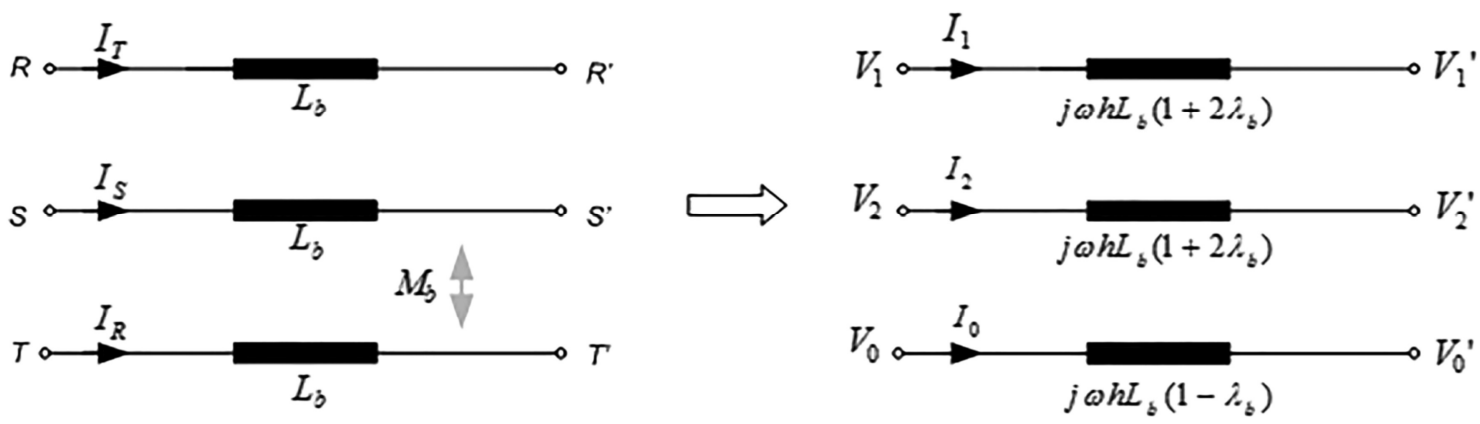

FIGURE 5 Decoupled sequential circuits of the ZSB

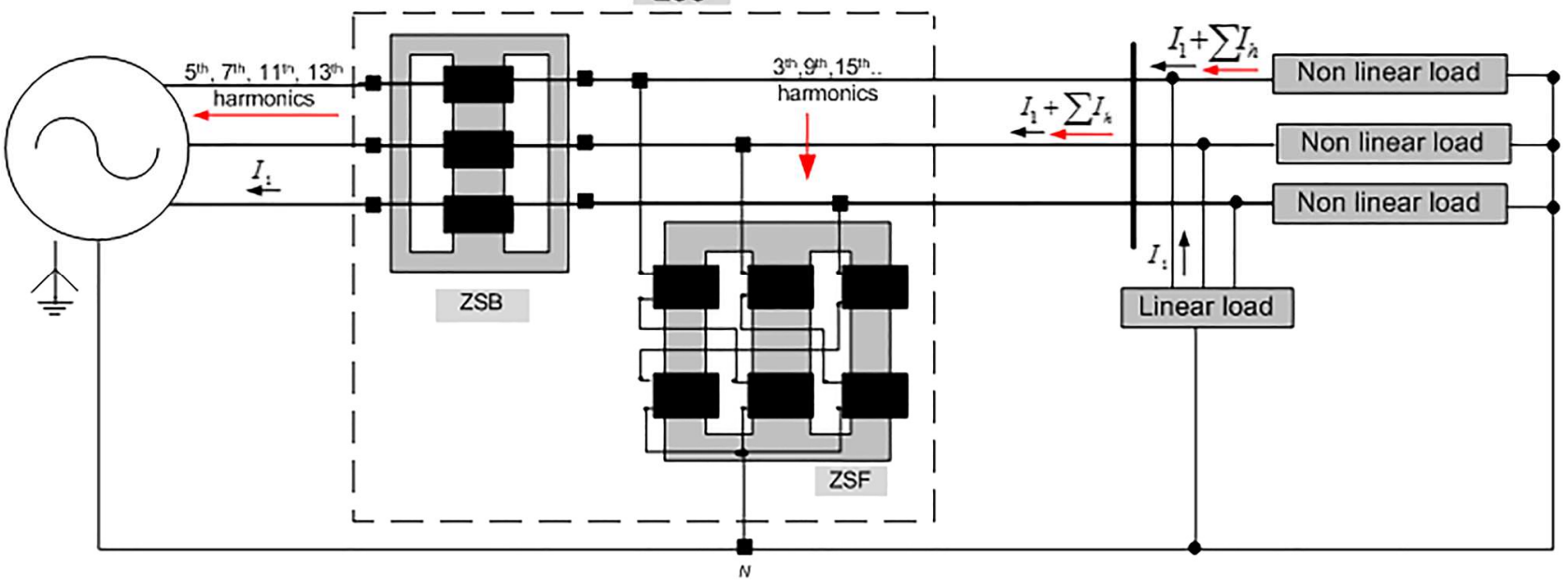

FIGURE 6 Installation of the ZSS composed by the ZSF and ZSB in a three-phase four-wire electrical power system

FIGURE 7 Equivalent circuit of the ZSS in an electrical power system

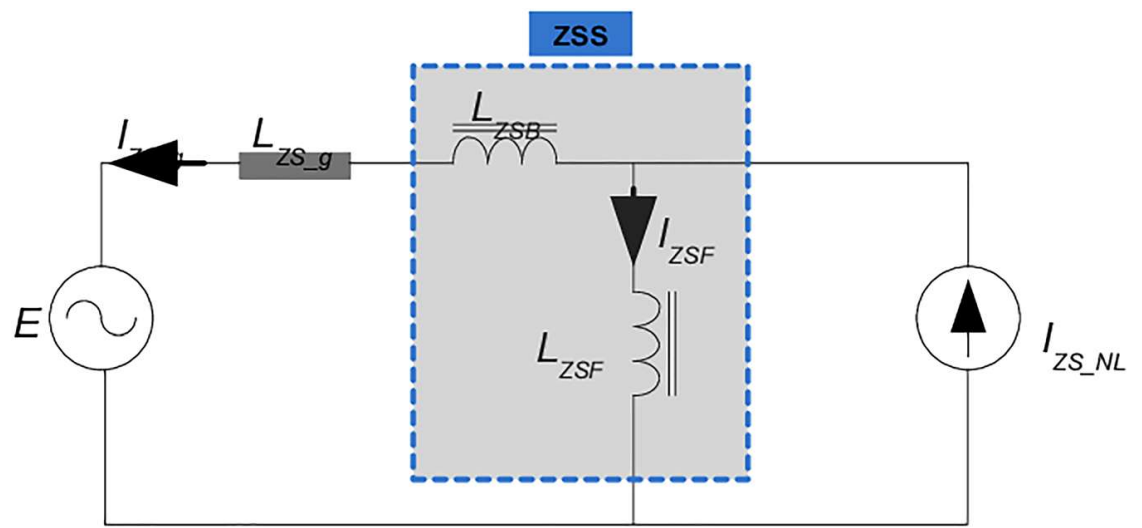


Assuming the similarity between the self-inductances of each coil $\left(L_{b}\right)$ and between the mutual inductances of the different phases coils $\left(M_{b}\right)$, it can be obtained the equations of the sequential voltages (5), (6), and (7).

$$
\begin{aligned}
& V_{1}^{h}=j \omega h\left[L_{b}-M_{b}\right] I_{1}^{h} \\
& V_{2}^{h}=j \omega h\left[L_{b}-M_{b}\right] I_{2}^{h}
\end{aligned}
$$

\begin{tabular}{|c|c|}
\hline Power & $6.7 \mathrm{kVA}$ \\
\hline Frequency & $50 \mathrm{~Hz}$ \\
\hline Maximum voltage on windings & $230 \mathrm{~V}$ \\
\hline Equivalent voltage on the coil & $200 \mathrm{~V}$ \\
\hline Maximum current on windings & $10 \mathrm{~A}$ \\
\hline Connection of the windings & Zig-Zag \\
\hline Lamination types & EI three-phase series \\
\hline Lamination material & Grain-oriented electrical steel \\
\hline Flux density & $1.37 \mathrm{~T}$ \\
\hline Section and material conductor & $4.2 \mathrm{~mm}^{2}$-Enameled copper \\
\hline Area product of magnetic core & $5062.5 \mathrm{~cm}^{4}$ \\
\hline Number of turns & 168 \\
\hline Inductance of coils & $300 \mathrm{mH}$ \\
\hline Resistance of coils & $0.193 \Omega$ \\
\hline Coupling factor between the coils & 0.99 \\
\hline
\end{tabular}

TABLE 1 Constructive and electrical characteristics of the ZSF prototype

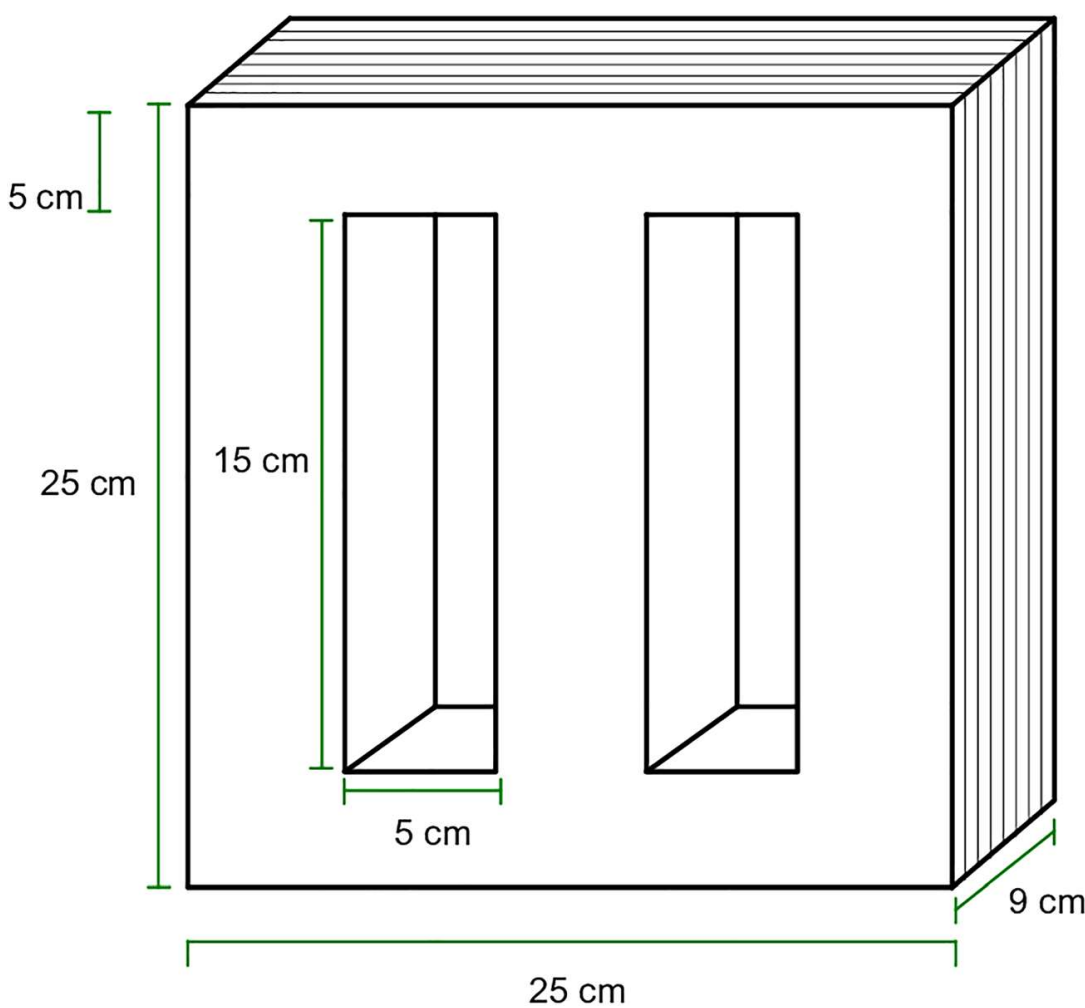

FIGURE 8 Developed prototype of the ZSF: A, dimensions of the EI laminated core; $\mathrm{B}$, overview of the $\mathrm{ZSF}$ 


$$
V_{0}^{h}=j \omega h\left[L_{b}+2 M_{b}\right] I_{0}^{h}
$$

It can be observed in Equation (7) that the ZSB provides a high equivalent inductance for the zero-sequence components and, simultaneously, offers low equivalent inductance for the positive and negative sequences. For this, it is necessary to obtain a maximum coupling between the coils, in such a way that self-inductances, $L_{b}$, and mutual inductances, $M_{b}$, are very similar. Equation (8) expresses the relationship between the mutual and self-inductances through a coupling factor.

$$
M_{b}=\lambda_{b} L_{b}
$$

Where:

$\lambda_{b}$ - coupling factor between the ZSB coils;

$L_{b}$ - self-inductance of the ZSB coils.

TABLE 2 Constructive and electrical characteristics of the ZSB prototype

\begin{tabular}{|ll}
\hline Power & $\mathbf{1 . 1} \mathbf{~ k V A}$ \\
\hline Frequency & $50 \mathrm{~Hz}$ \\
\hline Maximum voltage on windings & $15 \mathrm{~V}$ \\
\hline Maximum current on windings & $22 \mathrm{~A}$ \\
\hline Lamination types & EI single-phase series \\
\hline Lamination material & Siliceous steel (oriented grain) \\
\hline Flux density & $1.2 \mathrm{~T}$ \\
\hline Section and material conductor & $3.3 \mathrm{~mm}{ }^{2}-$ Enameled copper \\
\hline Area product of magnetic core & $468.75 \mathrm{~cm}^{4}$ \\
\hline Number of turns & 22 \\
\hline Inductance of coils & $5 \mathrm{mH}$ \\
\hline Resistance of coils & $0.023 \Omega$ \\
\hline Coupling factor between the coils & 0.99 \\
\hline
\end{tabular}

FIGURE 9 Developed prototype of the ZSB: A, dimensions of the used EI laminated core; B, overview of the ZSB

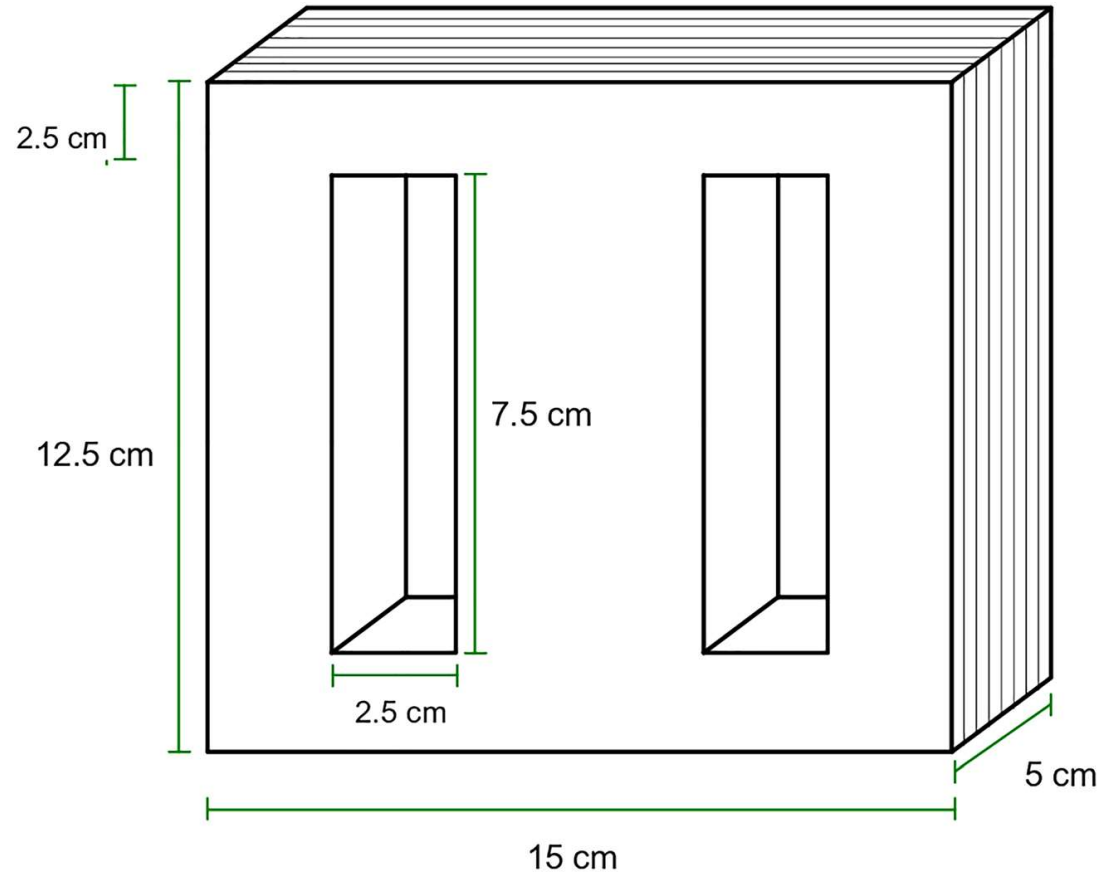




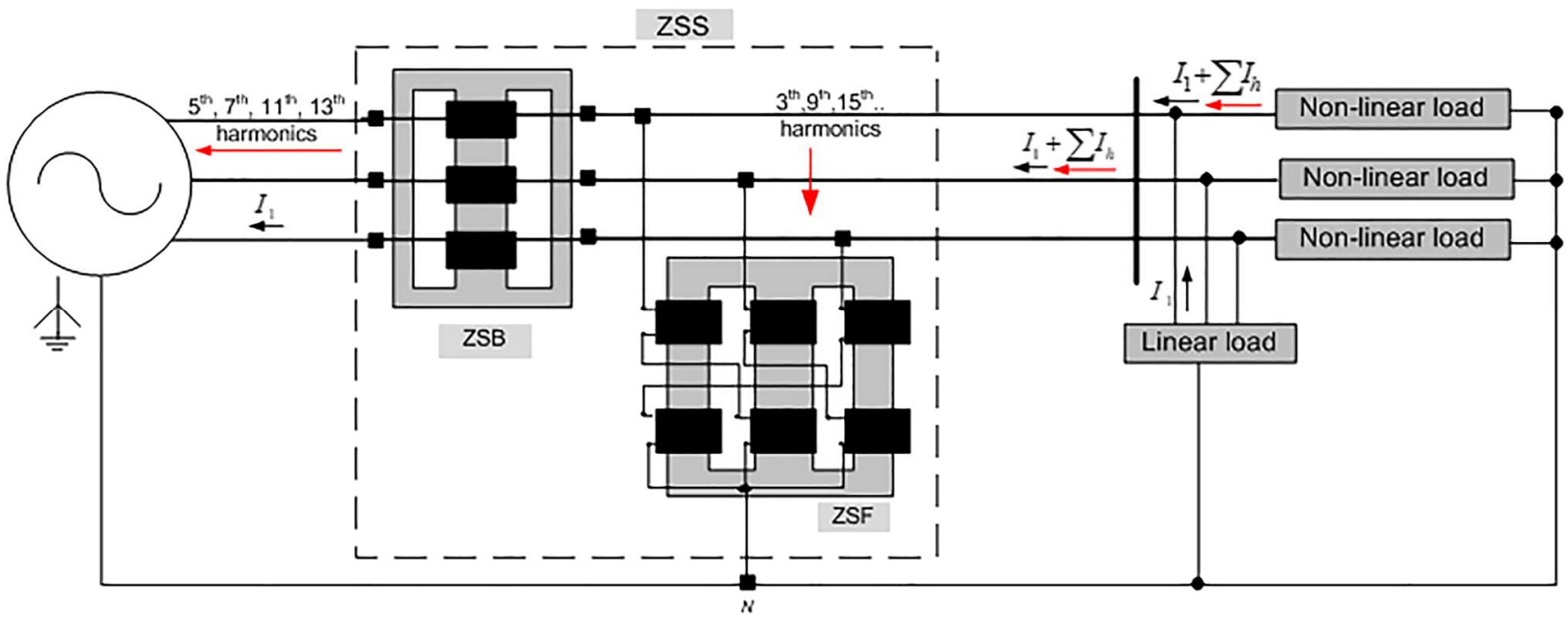

FIGURE 10 Schematic of the test platform implemented for experimental studies

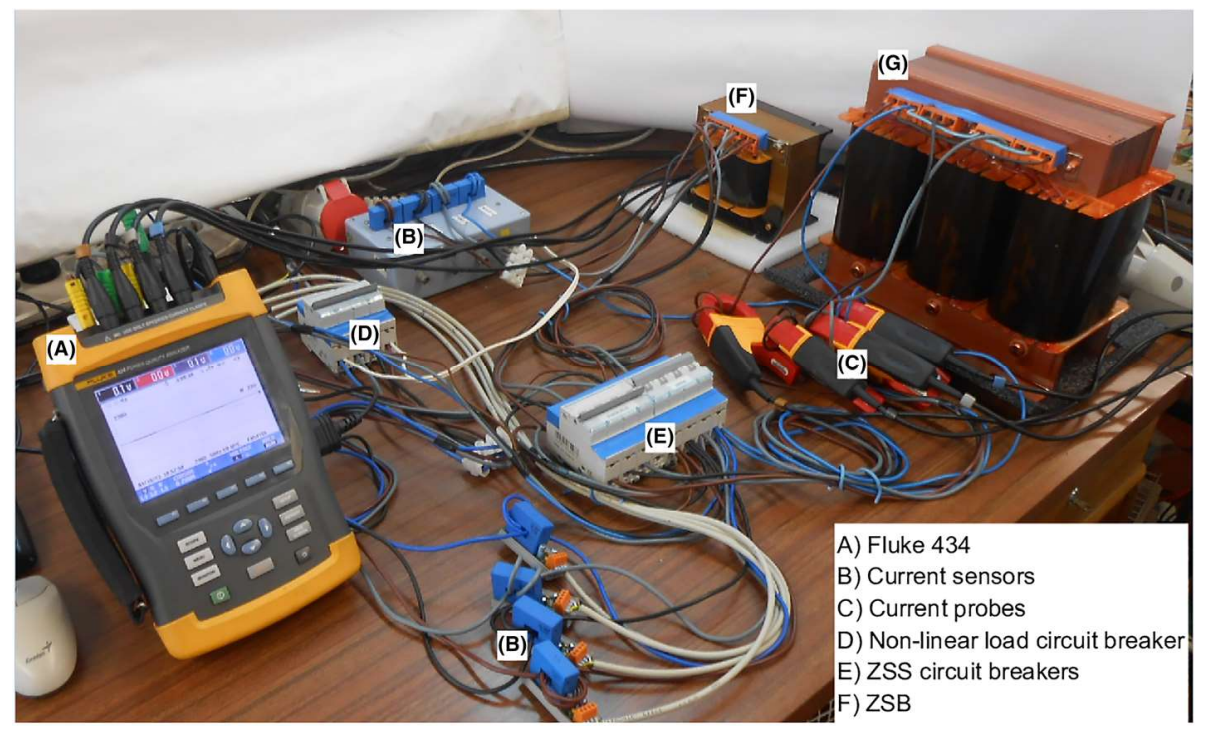

FIGURE 11 General overview of the workbench used in the experimental tests

TABLE 3 Selected experimental test cases

\begin{tabular}{llll} 
Cases & Load & ZSB-k1 & ZSF-k2 \\
\hline $\mathbf{1}$ & Balanced & Off & Off \\
$\mathbf{2}$ & Balanced & On & On \\
\hline $\mathbf{3}$ & Unbalanced & Off & Off \\
$\mathbf{4}$ & Unbalanced & On & On \\
\hline
\end{tabular}


In order to obtain an equality between the values of self and mutual inductances, it is necessary an ideal coupling, $\lambda_{b}$ $=1$. Thus, for zero-sequence, the self and mutual inductances add, resulting in an inductance three times greater. The opposite happens for the positive and negative sequences, where the self and mutual inductances cancel each other, forming a low impedance path for these components. Figure 5 shows the analysis from the point of view of the equivalent sequential circuits for an ideal coupling between the coils.

These characteristics reveal the blocking of the zero-sequence components, whose effectiveness is proportional to the coupling factor, and is ideally $\lambda_{b}=1$.

(A)

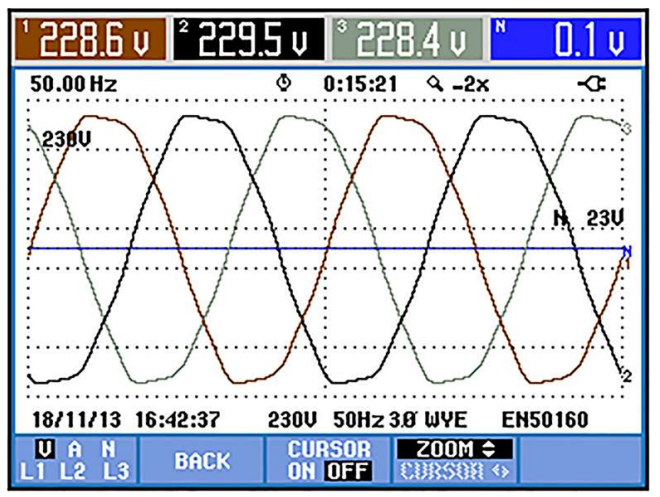

(C)

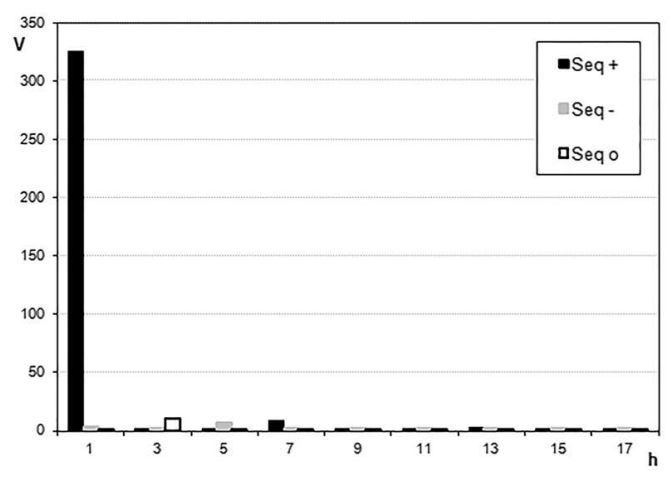

(E)

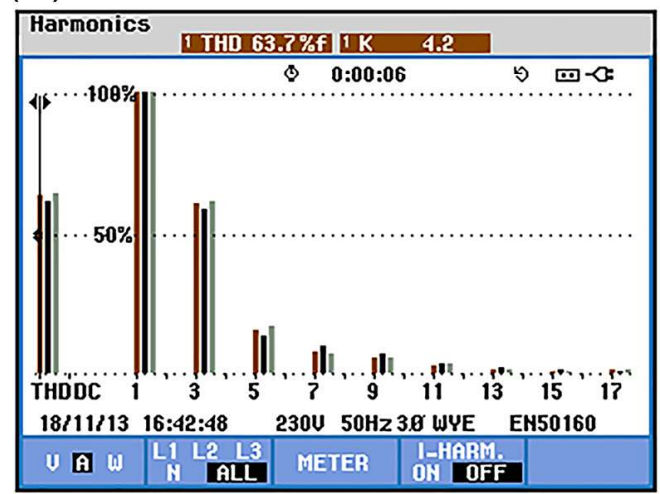

(B)

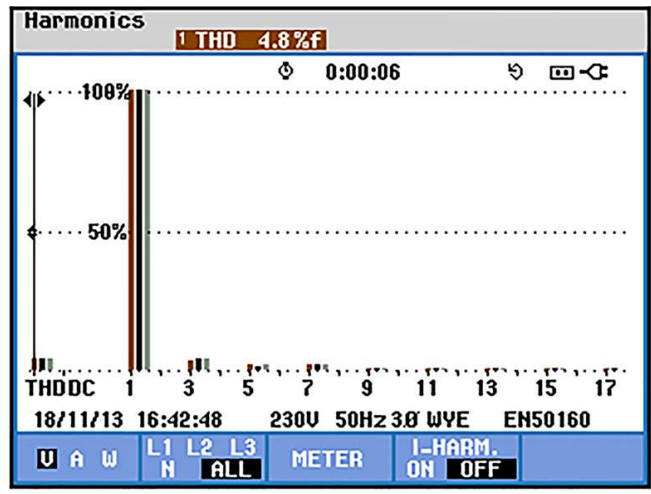

(D)

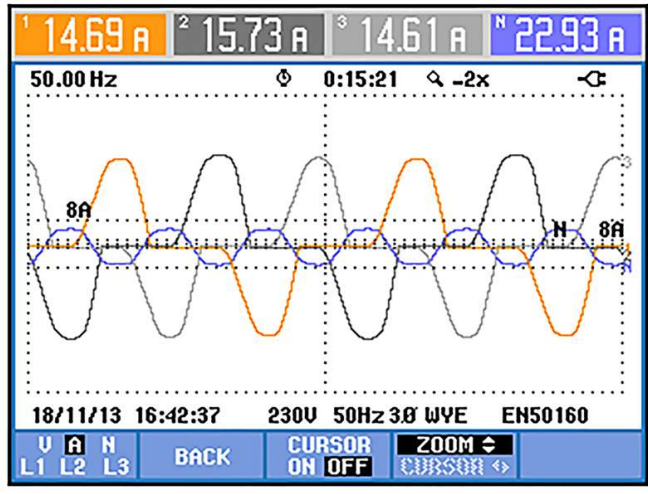

(F)

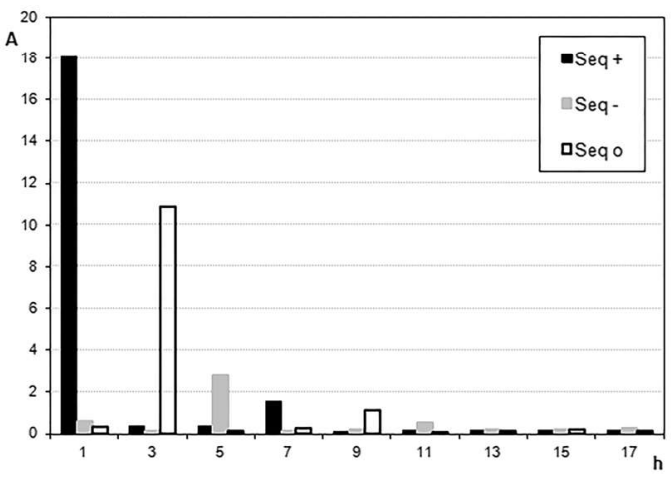

FIGURE 12 Experimental results without ZSS and with balanced loads: A, source voltages; B, harmonic spectrum of the source voltages; $\mathrm{C}$, sequential spectrum of the source voltages; D, source currents; E, harmonic spectrum of the source currents; F, sequential spectrum of the source currents 


\section{5 | HARMONIC COMPENSATION}

In order to reinforce the understanding related to the physical concepts of the harmonic compensation provided by the proposed combined electromagnetic arrangement, a brief explanation of the performance of the ZSS is presented.

Figure 6 shows that there is a connection between the zero-sequence inductances of the ZSF (in parallel), $L_{Z S F}$, and the ZSB (series), $L_{Z S B}$, as proposes the simplified equivalent zero-sequence circuit shown in Figure 7.

Equation (4) expresses the relationship between the mutual inductances to the coupling factor among the superior and inferior coils of the same magnetic column of the ZSF. In this logic, Equation (9) shows the conformity factor of the ZSF, $\xi_{f}$, denomination attributed in this paper to highlight the indispensable constructive similarities of the windings of the superior and inferior coils of the same magnetic column $\left(L_{S f}=L_{I f}\right)$.

$$
\xi_{f}=\frac{L_{S f}}{L_{I f}}
$$

Then, the zero-sequence inductance of the ZSF is given by

$$
L_{Z S F}=L_{f}\left(1-\lambda_{f} \sqrt{\xi_{f}}\right) .
$$

In the case of ZSB, Equation (6) expresses the relationship between the self and mutual inductances by means of a coupling factor. Again, as in the case of the ZSF, and in order to emphasize the constructive similarity of the windings between the coils of each of the three phases $(R, S$, and $T)$ of the blocker, the compliance factor, $\xi_{b}$, is shown in Equation (11).

$$
\xi_{b}=L_{R} / L_{S} / L_{T}
$$

Equation (11) shows the characteristic inductance of ZSB.

$$
L_{b}=L_{R}=L_{S}=L_{T}
$$

Then, the zero-sequence inductance of the ZSB can be determined by Equation (13).

$$
L_{Z S B}=L_{b}\left(1+2 \lambda_{b} \sqrt{\xi_{b}}\right)
$$

Considering, for simplicity, only the inductances and based on the principle of the current divider, the portion of zerosequence current produced by the load, $I_{Z S}{ }^{-}{ }_{N L}$, that flows through the ZSF, $I_{Z S F}$, can be determined by Equation (14).

(A)

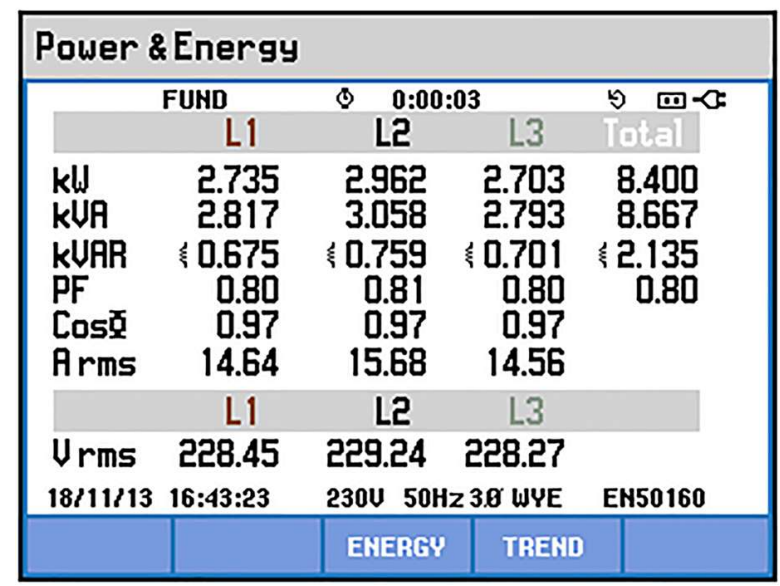

(B)

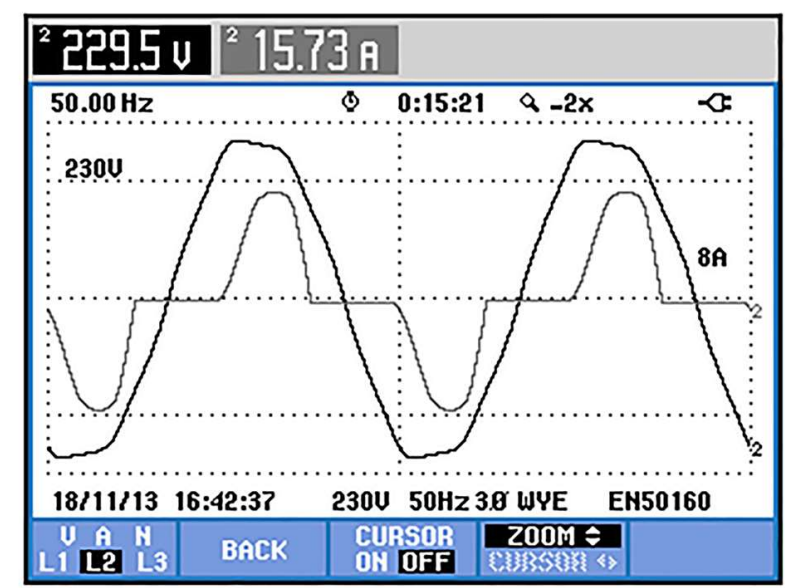

FIGURE 13 Experimental test results without ZSS, with balanced loads: A, power source details; B, voltage and current in one of the phases at source side 


$$
I_{Z S F}=\frac{L_{Z S^{-g}}}{\left(L_{Z S^{-} g}+L_{Z S B}\right)+L_{Z S F}} I_{Z S N L}
$$

where $L_{Z S}{ }^{-g}$ is the zero-sequence equivalent inductance of the electrical power grid.

Equation (13) shows that as lower is the zero-sequence inductance of the ZSF, in relation to the same inductance of the electrical power grid and of the ZSB, greater is the effectiveness in draining zero-sequence harmonic currents.

On the other hand, the resulting current at source, $I_{Z S}{ }^{-}$, can be calculated by Equation (14).

$$
I_{Z S^{-} g}=\frac{L_{Z S F}}{\left(L_{Z S g}+L_{Z S B}\right)+L_{Z S F}} I_{Z S^{-} N L}
$$

(A)

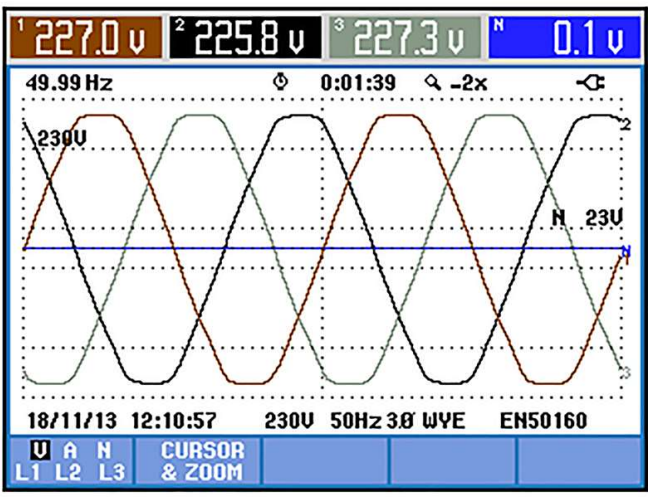

(C)

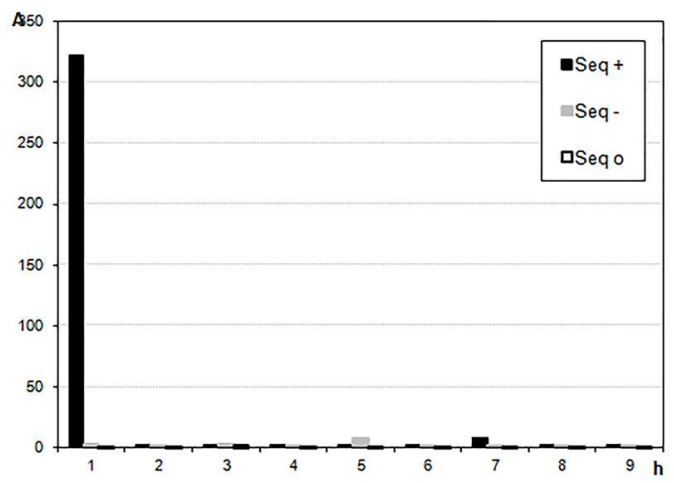

(E)

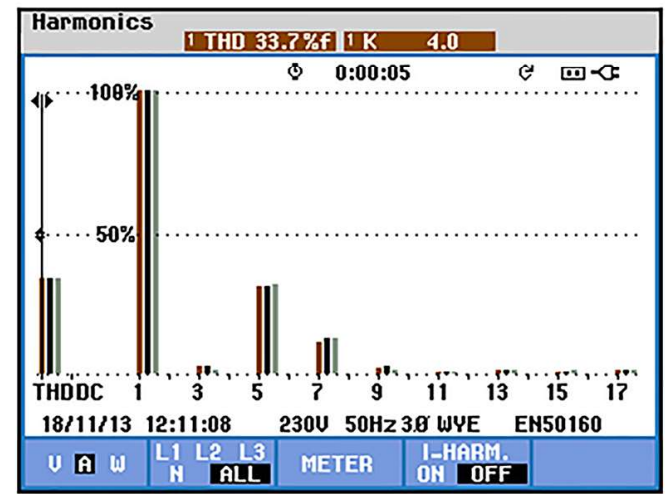

(B)

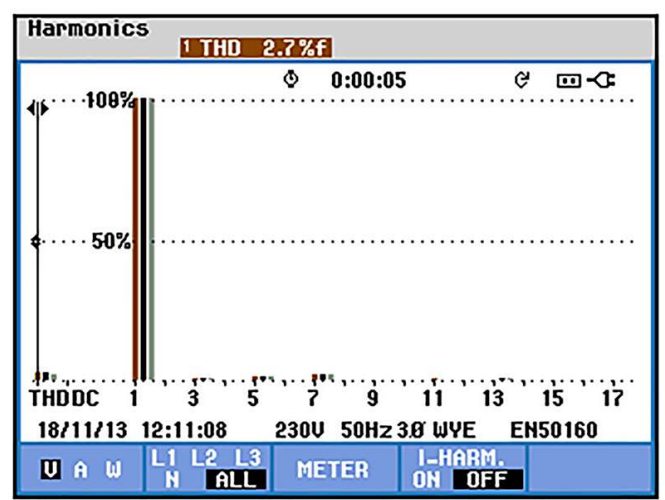

(D)

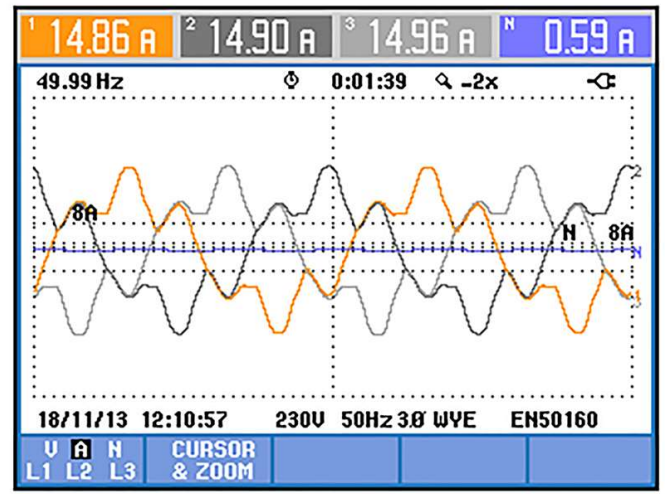

(F)

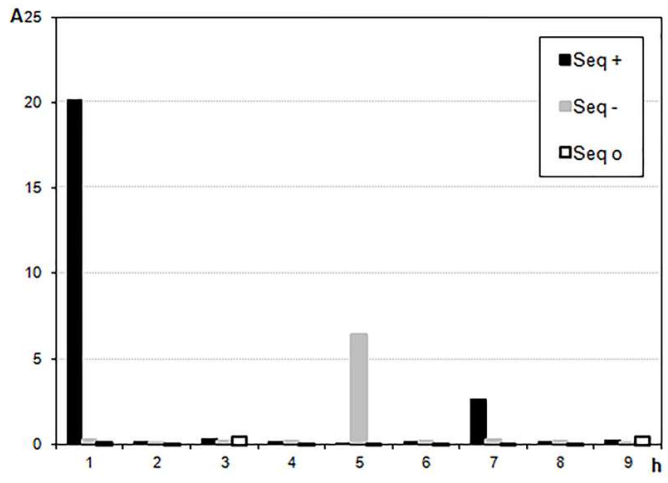

FIGURE 14 Experimental test results with ZSS and balanced loads: A, source voltages; B, harmonic spectrum of the source voltages; C, sequential spectrum of the source voltages; D, source currents; E, harmonic spectrum of the source currents; F, sequential spectrum of the source currents 
Equation (14) can still be rewritten as in Equation (16).

$$
\frac{I_{Z S^{-g}}}{I_{Z S N L}}=\frac{L_{f}\left(1-\lambda_{f} \sqrt{\xi_{f}}\right)}{L_{f}\left(1-\lambda_{f} \sqrt{\xi_{f}}\right)+L_{b}\left(1+2 \lambda_{b} \sqrt{\xi_{b}}\right)+\left(V_{n}{ }^{2} / \omega S_{c c}\right)}
$$

Equation (15) reaffirms that the current flowing in the power grid will be so smaller the higher the system and the ZSB zero-sequence inductances when compared with the ZSF zero-sequence inductance. Thus, the efficiency of the system in zero-sequence compensation can be compromised by the power grid characteristics in which it is installed.

\section{I DESIGN AND IMPLEMENTATION}

In order to conduct the experimental investigation of the ZSS, a prototype of a ZSF and a prototype of a ZSB were developed, based on the reference of power transformers design. ${ }^{22}$ In addition to the aspects related to the power level to be processed and the nominal voltage established, it is necessary to consider the other constructive aspects necessary to achieve the desired functionality of the electromagnetic devices.

\section{1 | ZSF prototype}

For the ZSF dimensioning, based on the theoretical model presented in Section 2, it is verified that the equivalent inductance of zero-sequence tends to a minimum value when the superior and inferior coils are similar, from the point of view of their self-inductances, and that the magnetic coupling between them comes close to the ideal. It is important to note that, in order to guarantee the maximum adopted flux density, the equivalent voltage composed by the superior and inferior coils of each column of the magnetic core which are supplied by different phases must be considered.

A ZSF prototype was constructed taking into account the constructive and electrical characteristics presented in Table 1 . These values consider a ZSB core and windings losses of about $10 \%$.

As mentioned previously, on the mathematical models section, the optimization of the device functionality as ZSF depends mainly on the maximization of the magnetic coupling between the superior and inferior coils of the same magnetic column. In this context, in order to achieve the best coupling in the construction of the coils, in addition to the adoption of concentric windings, a particular constructive technique was used, where each loop is composed of the conductors of each of the windings juxtaposed. In contrast, for positive and negative sequence inductances, it is desirable that they be maximized, so the interference of the ZSF in the system will be small as possible. Figure 8 shows the geometric representation of the used EI laminated core and an overview of the ZSF developed prototype.

(A)

\begin{tabular}{|c|c|c|c|c|}
\hline \multicolumn{5}{|c|}{ Power \& Energy } \\
\hline & $\begin{array}{l}\text { FUND } \\
\text { L1 }\end{array}$ & $\begin{array}{l}0: 00 \\
\text { L2 }\end{array}$ & L3 & $\Leftrightarrow$ \\
\hline $\begin{array}{l}\text { kUJ } \\
\text { kUR } \\
\text { kURR } \\
\text { PF } \\
\text { Cos } \\
\text { Rrms }\end{array}$ & $\begin{array}{r}3.048 \\
3.182 \\
\{0.912 \\
0.91 \\
0.96 \\
14.78\end{array}$ & $\begin{array}{r}3.032 \\
3.170 \\
\{0.924 \\
0.91 \\
0.96 \\
14.81\end{array}$ & $\begin{array}{r}3.085 \\
3.211 \\
0.890 \\
0.91 \\
0.96 \\
14.90\end{array}$ & $\begin{array}{r}9.165 \\
9.562 \\
2.726 \\
0.91\end{array}$ \\
\hline \multirow[t]{2}{*}{$\begin{array}{l}\text { Urms } \\
18 / 11113\end{array}$} & $\begin{array}{c}\text { L1 } \\
227.06 \\
12: 11: 45\end{array}$ & $\begin{array}{c}\text { L2 } \\
225.78 \\
230 \cup \quad 50\end{array}$ & $\begin{array}{c}\text { L3 } \\
227.46 \\
23.8 \text { WYE }\end{array}$ & EN50160 \\
\hline & & EHEREY & TRESD & \\
\hline
\end{tabular}

(B)

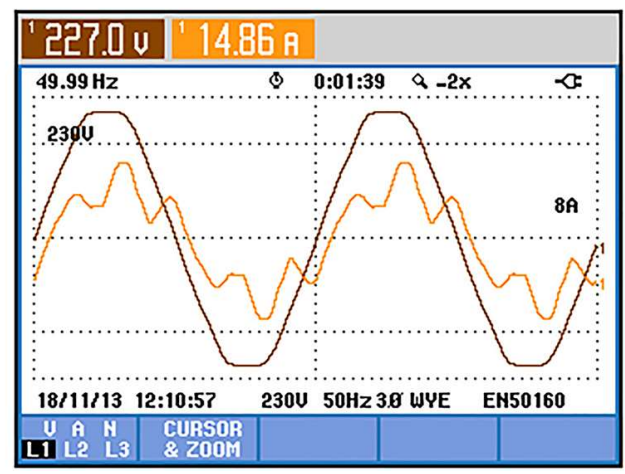

FIGURE 15 Experimental results with ZSS and balanced loads: A, power source details; B, voltage and current in one of the source phases 


\section{2 | ZSB prototype}

For the ZSB dimensioning, based on the theoretical model presented in Section 2, it is verified that the coupling between the windings of the coils approach in such a way that the self and their mutual inductances are equal and, consequently, the device will provide a high zero-sequence impedance, thus blocking these components. For the equality between self and mutual inductances, an ideal coupling is needed, which increases the blocking efficiency of zero-

(A)

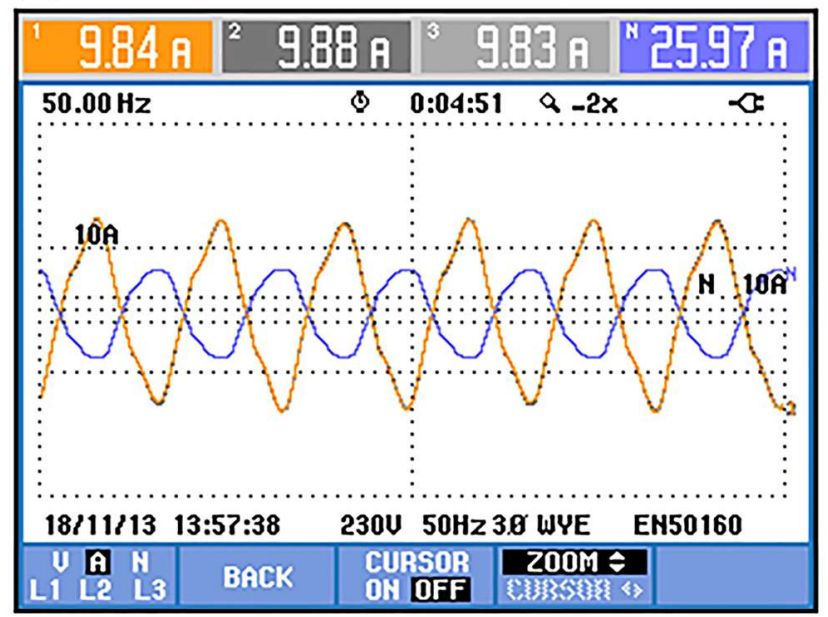

(B)

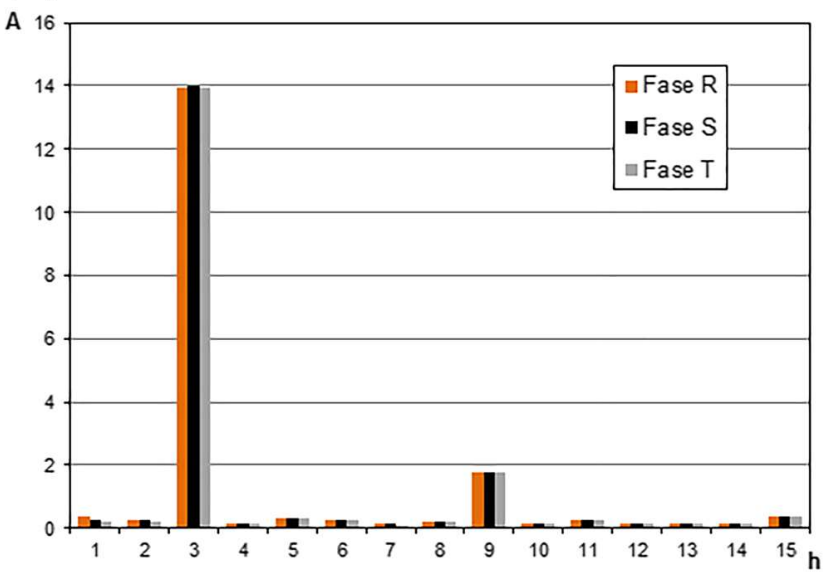

(C)

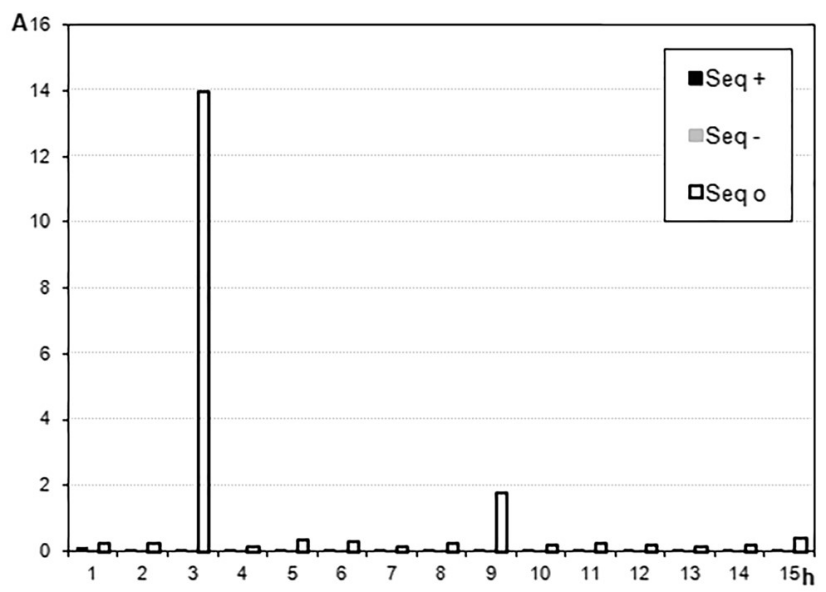

FIGURE 16 Experimental test results with ZSS and balanced loads: A, currents in the ZSF; B, harmonic spectrum of the currents in the ZSF; C, sequential spectrum of the currents in the ZSF 
sequence components and, for the other components, positive and negative sequence, the opposite happens, because a very low impedance is obtained.

Aiming the experimental investigation of the ZSB performance, a prototype has been constructed. The constructive and electrical characteristics considered in the ZSB construction are shown in Table 2. As in the ZSB prototype, these values consider a ZSB core and windings losses of about $10 \%$.

The procedure for coil and core design follow the same methodology used in the construction of the ZSF. As mentioned above, the device is designed from three magnetically coupled coils and arranged on the same core column. For this configuration, when connected in series with the grid, the ZSB present high impedance for the zero-sequence components and can minimize the circulation of triplen harmonics. Figure 9 shows the geometric representation of the used EI laminated core and an overview of the ZSB developed prototype.

\section{7 | EXPERIMENTAL RESULTS}

In order to analyze the performance of the proposed system, the schematic shown in Figure 10 was implemented as a platform for experimental tests. This platform is composed by a nonlinear load and the ZSS (composed by the ZSF and the ZSB).

As shown in Figure 10 for the composition of the three-phase nonlinear load, an arrangement with expressive concentration of zero sequence harmonics was chosen, but it also generates considerable amounts of positive and negative sequence harmonic currents. For this, a three-phase nonlinear load composed of three single-phase rectifiers based in the full-bridge topology was used, feeding variable resistive loads with capacitive filter.

The filtering devices and the loads were connected to a power grid with nominal voltage of $230 \mathrm{~V}, 50 \mathrm{~Hz}$. The acquisition and the processing of the captured signals was performed using the Fluke 434 Power Quality Analyzer and the FlukeView Power Quality Analyzer Version 3.34, respectively.

Figure 11 shows the overall view of the workbench for experimental tests.

The experiments contemplated in this paper were carried out for different arrangements of the system in steady state, having as main objective the investigation of the ZSS functionality. Looking for a synthetic and clear presentation, there are presented below the more representative results for the selected test cases, in which the focus is the ZSS behavior and performance. The operational conditions imposed for experimental tests are summarized in Table 3.

The results shown below are presented by means of the voltage and current waveforms, including their respective harmonic spectrum of phase and sequential components. The calculations of the sequential components and the respective DFTs (Discrete Fourier Transform) were performed using a spreadsheet developed in Microsoft Excel. For this purpose, 150 samples per grid cycle were extracted from the FlukeView Power Quality Analyzer for each period of interest. The power grid and load data are also displayed.

TABLE 4 Comparison between test cases 1 and 2

\begin{tabular}{|c|c|c|}
\hline & Case 1: Without ZSS & Case 2: With ZSS \\
\hline $\mathrm{THD}_{\mathrm{V}}(\%)$ & 4.2 & 2.7 \\
\hline THD $_{\text {I }}(\%)$ & 63.1 & 33.7 \\
\hline $\mathbf{I}_{\mathbf{N}}(\mathbf{A})$ & 22.93 & 0.59 \\
\hline PF & 0.8 & 0.91 \\
\hline
\end{tabular}

TABLE 5 Nonlinear load data

$\begin{array}{lr}\text { Rectifier-Phase } \boldsymbol{R} & \boldsymbol{R}_{\boldsymbol{R}}=\mathbf{5 2} \mathbf{\Omega} ; \boldsymbol{C}_{\boldsymbol{R}}=\mathbf{2 8 2 0} \boldsymbol{\mu} \mathbf{F} \\ \text { Rectifier-Phase } S & R_{S}=26 \Omega ; C_{S}=2820 \mu \mathrm{F} \\ \text { Rectifier-Phase } T & R_{T}=26 \Omega ; C_{T}=2820 \mu \mathrm{F}\end{array}$




\section{CASE 1. WITHOUT ZSS AND WITH BALANCED LOADS}

The purpose of this test case is to observe the harmonics produced by the loads, without the ZSS devices (ZSF and ZSB) connected. The load was fed directly from the power grid. These results are taken as reference for the comparative study of the filtering performance presented in test case 2, highlighting the waveforms and the harmonic spectrum of three-phase currents and voltages. Figure 12 illustrates the waveforms and the harmonic distortion levels of voltages and currents of the system.

The results obtained with the experiment indicate a total harmonic distortion of the voltage $\left(\mathrm{THD}_{\mathrm{V}}\right)$ of $4.2 \%$, calculated by the average of the $\mathrm{THD}_{\mathrm{V}}$ in each phase. The total current distortion $\left(\mathrm{THD}_{\mathrm{I}}\right.$ ) is $63.1 \%$ (average of the $\mathrm{THD}_{\mathrm{I}}$ in each phase). As expected, the third harmonic, with a strong concentration in zero sequence, presents the most relevant

(A)

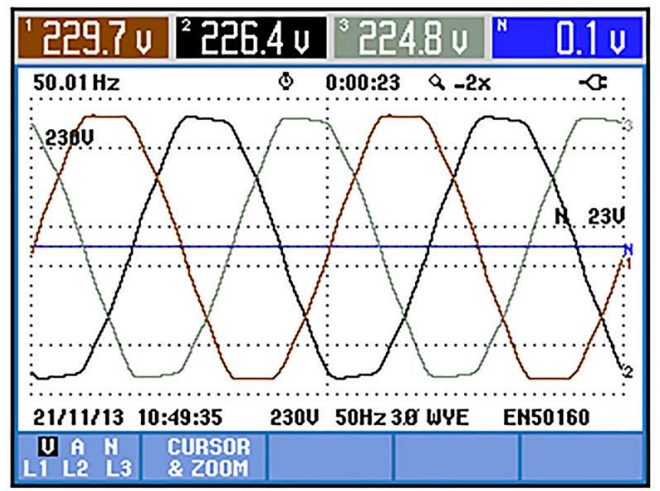

(C)

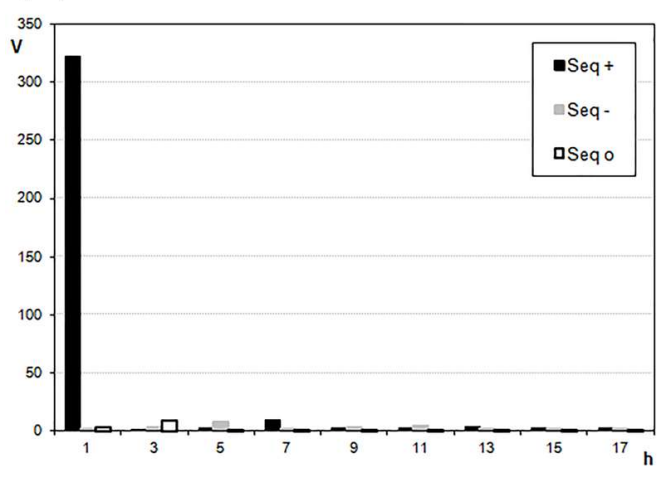

(E)

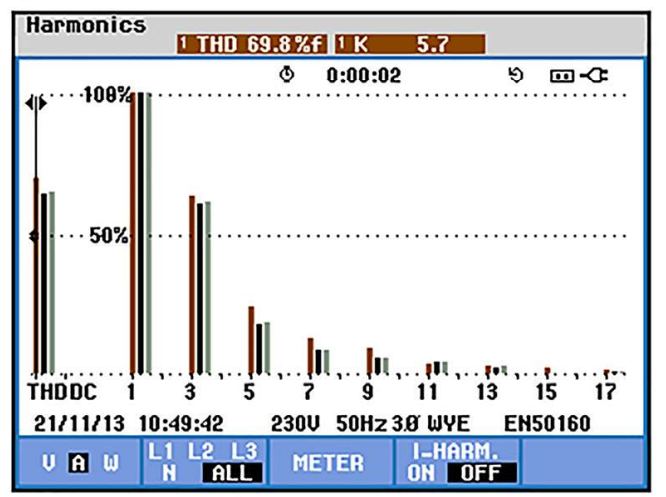

(B)

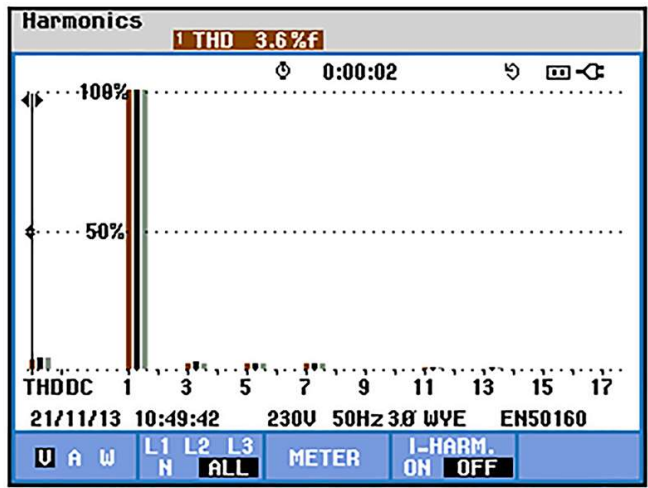

(D)

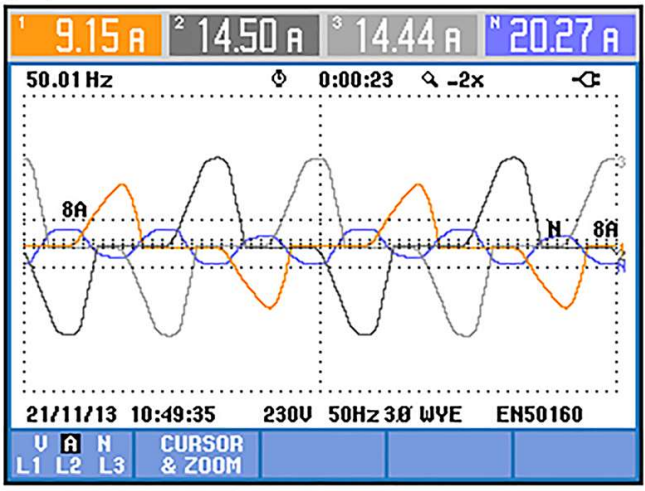

(F)

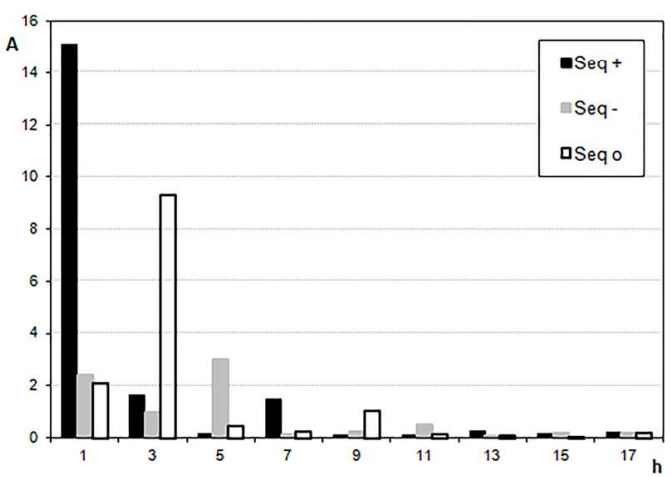

FIGURE 17 Experimental test results without ZSS and with unbalanced loads: A, source voltages; B, harmonic spectrum of the source voltages; C, sequential spectrum of the source voltages; D, source currents; E, harmonic spectrum of the source currents; F, sequential spectrum of the source currents 
amplitude. However, the fifth, seventh, and ninth harmonic orders have important contributions to the THD. It is also important to note that the value of the current in the neutral conductor $\left(I_{N}=22.93 \mathrm{~A}\right)$ exceeds the value of the currents in the phase conductors $\left(\mathrm{I}_{\mathrm{A}}=14.69 \mathrm{~A}\right)$.

As in this case, there is no ZSS connected between the source and the load, the active, reactive, and apparent powers, as well as the power factor are the same, regardless of the measuring point. The values of the active, reactive, and apparent power in the source, as well as the power factor, are presented in Figure 13. The power factor $(\mathrm{PF})$ obtained in this case is 0.80 and is fundamentally due to the harmonic distortion generated by the load.

\section{CASE 2. - WITH ZSS AND WITH BALANCED LOADS}

Figure 14 shows the values of the voltages and currents measured after the connection of the ZSS proposed in this paper.

By analyzing the results of the three-phase currents, the good performance of the ZSS is clear. The neutral current is reduced dramatically, and the zero-sequence current harmonics measured in the source side have very low value. Figure 15 shows the power measured in source considering the operation of the ZSS.

Figure 16 shows the waveforms of the currents that flow through the ZSF, where their homopolar characteristic is verified, with a predominating frequency in the third-order harmonic.

As predicted, the ZSF provides a path of low impedance for the zero-sequence harmonics. Thus, from the point of view of harmonics mitigation, this means that, under balanced operating conditions, all triplen harmonic currents are filtered by the ZSF. On the other hand, a high positive sequence impedance is provided in the design of the device, whereby a residual positive and/or negative sequence component flows through the ZSF.

To facilitate the visualization of the improvement provided by the ZSS, Table 4 presents a summary of the comparison between the test cases 1 and 2 .

\section{CASE 3. - NO ZSS, WITH UNBALANCED LOADS}

The purpose of this test case is to investigate the in a situation of load unbalance.

In this experiment, the configuration of the unbalance is caused by the change of the components in one of the single-phase loads; that is, in one of the single-phase rectifiers, the resistance was changed to $52 \Omega$ instead of the $26 \Omega$ used in the other two rectifiers. The new load configuration is shown in Table 5.

Figure 17 illustrates the waveforms of the three-phase source voltages and currents without the action of the ZSS. This case is taken as reference for the analysis of the test case 4.

Analyzing the voltages in the supply system, Figure 17, without the ZSS, it is possible to perceive a slight unbalance in the voltages caused by the imbalance imposed on the load. Observing the three-phase currents, shown in Figure 17D, it is possible to verify the unbalanced load characteristic. The same can be observed in the sequential spectrum of the harmonic currents, which also are not ideally distributed, Figure 17E,F.

The values of the power factor and the active, reactive, and apparent powers measured in the source are shown in Figure 18.

(A)

\begin{tabular}{|c|c|c|c|c|}
\hline \multicolumn{5}{|c|}{ Power \& Energy } \\
\hline \multirow{2}{*}{\multicolumn{2}{|c|}{ FUND }} & \multicolumn{2}{|c|}{$0: 0: 03$} & \multirow{2}{*}{ o 四人o } \\
\hline & L1 & L2 & L3 & \\
\hline \multirow[t]{2}{*}{$\begin{array}{l}\text { kUJ } \\
\text { kUR } \\
\text { kURR } \\
\text { PF } \\
\text { Cos } \\
\text { Rrms }\end{array}$} & $\begin{array}{r}2.735 \\
2.817 \\
\{0.675 \\
0.80 \\
0.97 \\
14.64\end{array}$ & $\begin{array}{r}2.962 \\
3.058 \\
\{0.759 \\
0.81 \\
0.97 \\
15.68\end{array}$ & $\begin{array}{r}2.703 \\
2.793 \\
0.701 \\
0.80 \\
0.97 \\
14.56\end{array}$ & $\begin{array}{r}8.400 \\
8.667 \\
\text { ₹ } 2.135 \\
0.80\end{array}$ \\
\hline & L1 & L2 & L3 & \\
\hline \multirow{3}{*}{$\begin{array}{l}\text { Urms } \\
18 / 11 / 13\end{array}$} & 228.45 & 229.24 & 228.27 & \\
\hline & $16: 43: 23$ & $230 \mathrm{U} 50 \mathrm{~Hz}$ & 3.8 WYE & EN50160 \\
\hline & & EYEREY & TREKID & \\
\hline
\end{tabular}

(B)

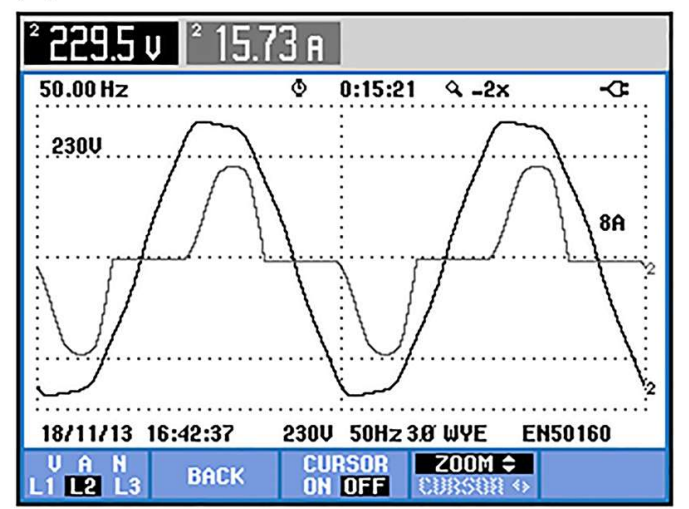

FIGURE 18 Experimental test results without ZSS and with unbalanced loads: A, power source details; B, voltage and current in one of the source phases 


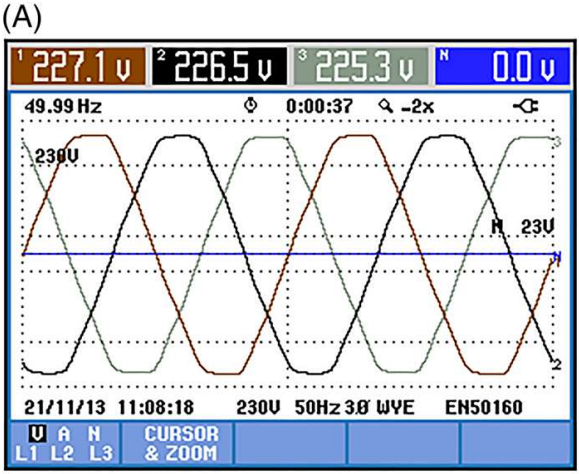

(C)

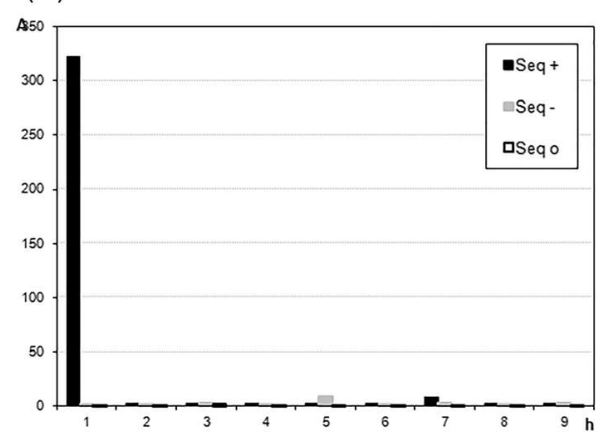

(E)

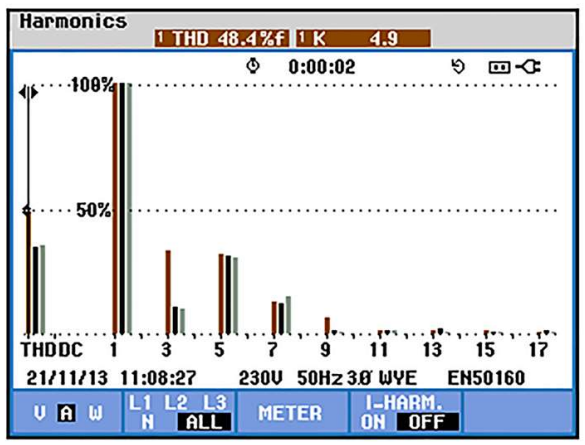

(B)

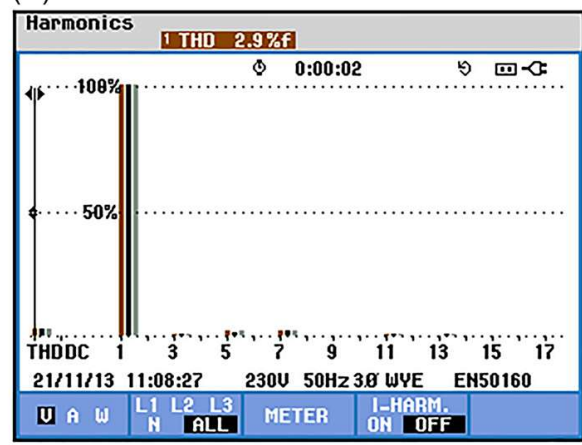

(D)

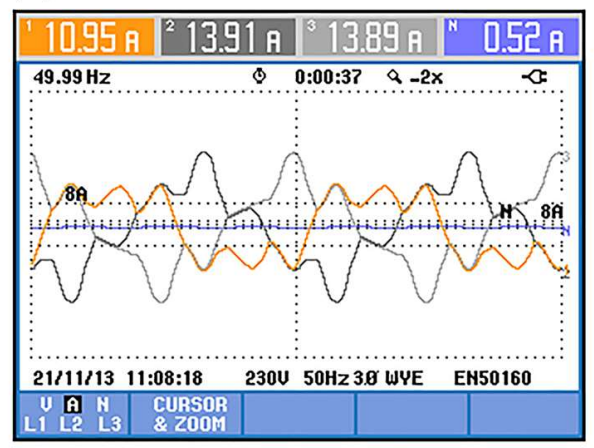

$(\mathrm{F})$

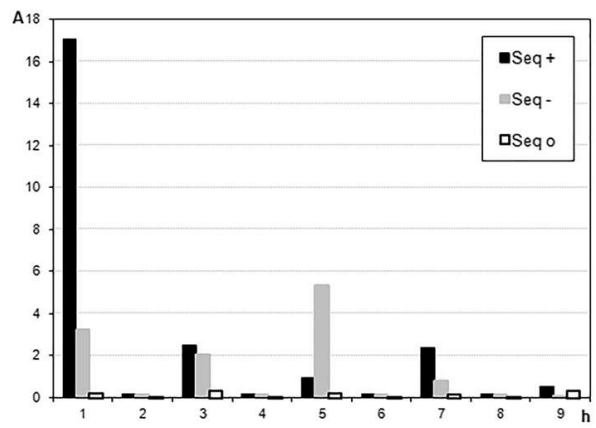

FIGURE 19 Experimental test results with ZSS and with unbalanced loads: A, source voltages; B, harmonic spectrum of the source voltages; C, sequential spectrum of the source voltages; D, source currents; E, harmonic spectrum of the source currents; F, sequential spectrum of the source currents

(A)

\begin{tabular}{|c|c|c|c|c|}
\hline \multicolumn{5}{|c|}{ Power \& Energy } \\
\hline & $\begin{array}{l}\text { FUMD } \\
\text { L1 }\end{array}$ & $\begin{array}{l}0: 00: \\
\text { L2 }\end{array}$ & L3 & $\checkmark$ 四心 \\
\hline $\begin{array}{l}\text { KWJ } \\
\text { kUR } \\
\text { kUAR } \\
\text { PF } \\
\text { Cos } \\
\text { Prms }\end{array}$ & $\begin{array}{r}2.136 \\
2.229 \\
\{0.639 \\
0.86 \\
0.96 \\
10.89\end{array}$ & $\begin{array}{r}2.937 \\
2.965 \\
\{0.406 \\
0.94 \\
0.99 \\
13.85\end{array}$ & $\begin{array}{r}2.653 \\
2.943 \\
\{1.274 \\
0.85 \\
0.90 \\
13.84\end{array}$ & $\begin{array}{r}7.726 \\
8.137 \\
\{2.319 \\
0.89\end{array}$ \\
\hline \multirow[t]{2}{*}{$\begin{array}{l}\text { Urms } \\
21 / 11 / 13\end{array}$} & $\begin{array}{c}L 1 \\
227.25 \\
11: 09: 09\end{array}$ & $\begin{array}{c}\text { L2 } \\
226.54 \\
2300 \quad 50 \mathrm{H}\end{array}$ & $\begin{array}{c}\text { L3 } \\
225.42 \\
238 \text { WYE }\end{array}$ & EN50160 \\
\hline & & ENEREY & TREAID & \\
\hline
\end{tabular}

(B)

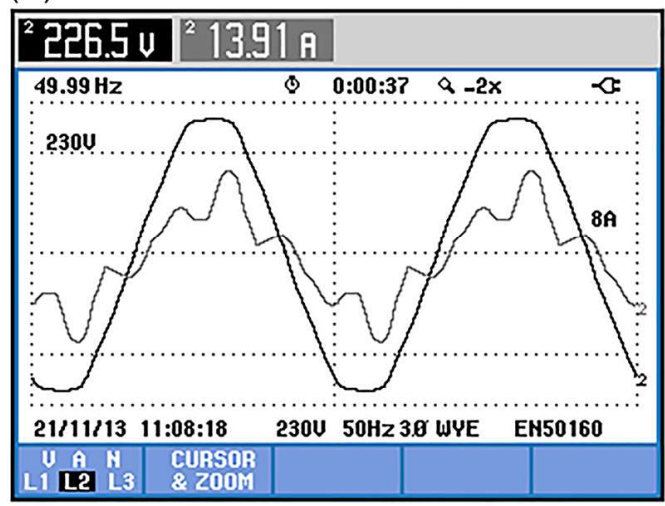

FIGURE 20 Experimental test results with ZSS and with unbalanced loads: A, power source details; B, voltage and current in one of the source phases 


\section{CASE 4. - WITH ZSS AND WITH UNBALANCED LOADS}

Figure 19 shows the three-phase voltages and current measured in the source side with the ZSS connected to the power system, considering load unbalance.

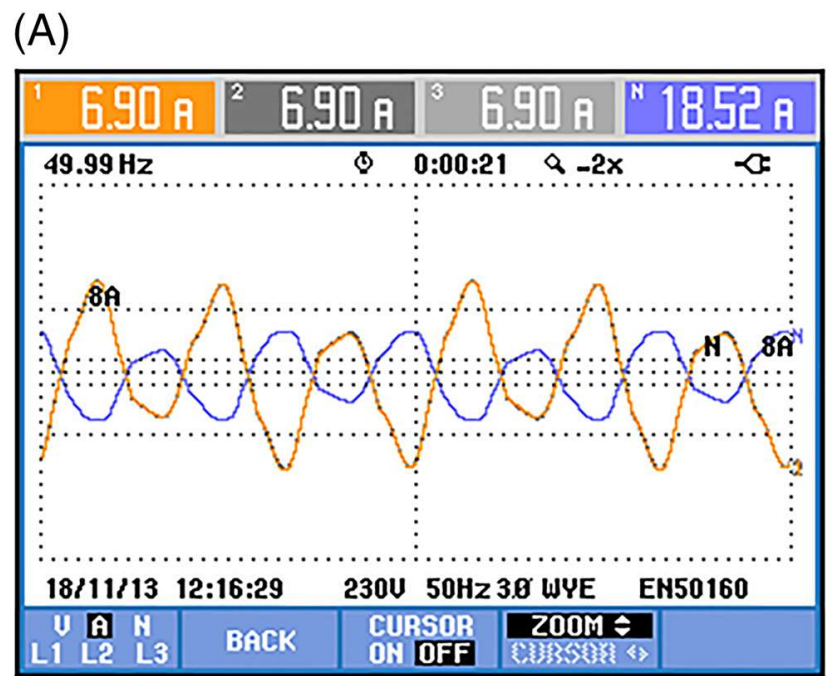

(B)

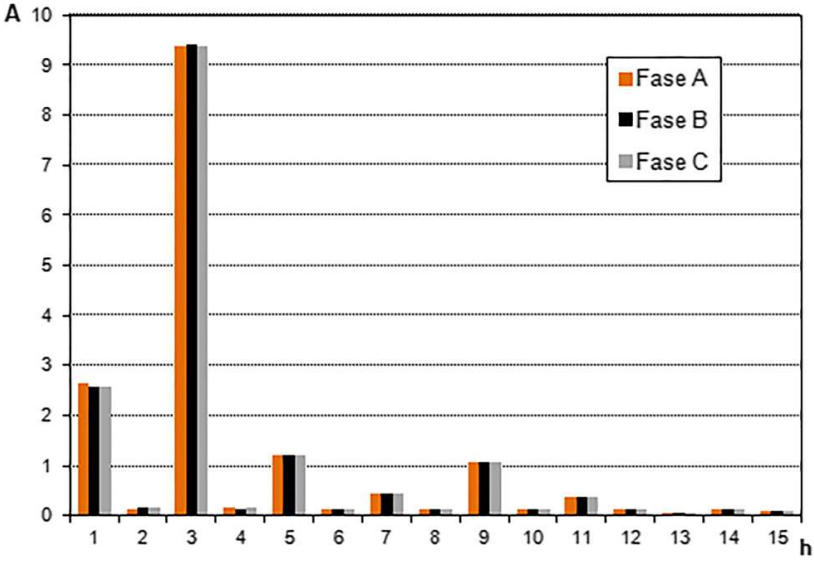

(C)

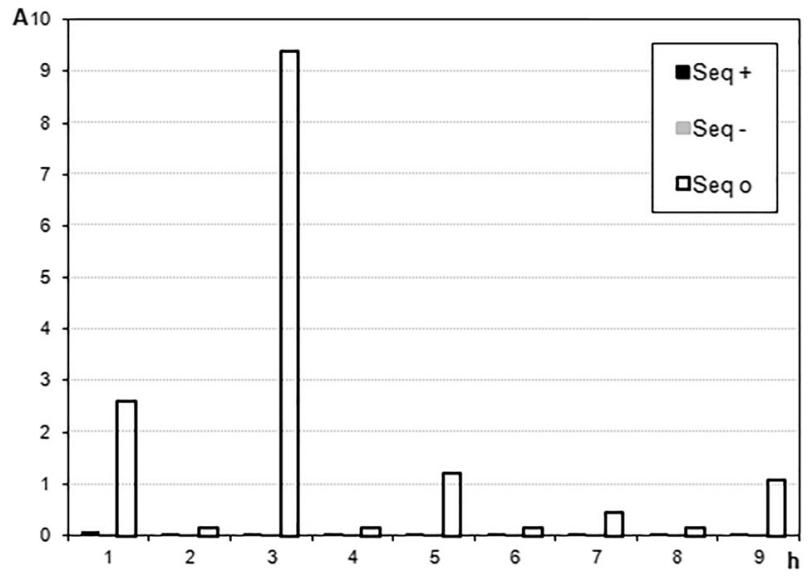

FIGURE 21 Experimental results with ZSS and with unbalanced loads: A, currents in the ZSF; B, harmonic spectrum of the currents in the ZSF; C, sequential spectrum of the currents in the ZSF 
TABLE 6 Comparison between test cases 3 and 4

\begin{tabular}{llr} 
& Case 3: Without ZSS & Case 4: With ZSS \\
\hline THD $_{\mathbf{V}}(\%)$ & $3.6 \%$ & $2.9 \%$ \\
\hline THD $_{\mathbf{I}}(\%)$ & $69.8 \%$ & $48.4 \%$ \\
\hline $\mathbf{I}_{\mathbf{N}}(\mathbf{A})$ & 20.27 & 0.52 \\
$\mathbf{P F}$ & 0.8 & 0.89 \\
\hline
\end{tabular}

Figure 20 shows the power measured in the source considering the operation of the ZSS and the voltage and current signals in one phase of the three-phase system.

Figure 21 shows the waveforms of the currents in the ZSF, with a strong zero-sequence concentration.

It is found that the ZSF provides a low impedance path for the circulation of zero-sequence harmonic currents, even under unbalanced load operating conditions. It is verified that the triplen harmonic currents are filtered by the ZSF.

The summary of the comparison between the test cases 3 and 4 is presented in Table 6 .

\section{8 | CONCLUSIONS}

The investigations and findings presented in this paper were particularly directed to the experimental investigation of the integrated operation of the electromagnetic devices that compose a proposed zero-sequence current suppressor (ZSS). This electromagnetic arrangement, composed by a zero sequence filter (ZSF) and a zero-sequence blocker (ZSB), was designed with the purpose of minimizing the flow of zero-sequence components in three-phase four-wire distribution systems.

During the experiments, the ZSS and the loads were connected directly to the power grid, in a $230-\mathrm{V}$ phase-toneutral, $50-\mathrm{Hz}$ system (low voltage distribution system in Europe). There were investigated situations considering balanced (ideal) and unbalanced (nonideal) operating conditions, using nonlinear loads with high content of zerosequence components. In these conditions, the experimental results showed a very good performance of the ZSS, which reduced substantially the circulation of the zero-sequence current harmonics towards the source, especially for operation with balanced load.

The modification in the nonlinear loads parameters to obtain an unbalanced system generated severe imbalances in the currents, which increased the total harmonic distortions of the source currents and voltages. With the inclusion of the ZSS, the problems were significantly reduced, revealing a satisfactory performance of the ZSS, even in unfavorable operating conditions.

The connection of the ZSS produced good results in all tests performed, thus being presented as an effective solution to mitigate power quality problems in electrical installations with high neutral currents and zero-sequence harmonics.

\section{ACKNOWLEDGEMENTS}

This work has been supported by CNPq - National Council for Scientific and Technological Development, by CAPES Coordinationfor the Improvement of Higher Education Personnel through the PDSE - Doctoral Program Sandwich Abroad 7427-12-3, and by FCT - Foundation for Science and Technology within the Project Scope: UID/CEC/00319/ 2019 and FCT within project PTDC/EEI-EEE/28813/2017.

\section{FUNDING INFORMATION}

. CNPq-NationalCouncil for Scientific and Technological Development, CAPES-Coordination forthe Improvement of Higher Education Personnel and FCT - Foundation for Scienceand Technology. 


\section{ORCID}

Stefani Carolline Leal Freitas (D) https://orcid.org/0000-0002-2641-8283

\section{REFERENCES}

1. Czarnecki LS. Harmonics and power phenomena. Wiley Encyclopedia of Electrical and Electronics Engineering. 1999. https://doi.org/ 10.1002/047134608X.W3711

2. Kumar D, Zane F. Harmonic analysis of grid connected power electronic systems in low voltage distribution networks. In IEEE Journal of Emerging and Selected Topics in Power Electronics. 2015, 2016;4:70-79. https://doi.org/10.1109/JESTPE.2015.245453

3. Sharma H, Rylander M, Dorr D. Grid impacts due to increased penetration of newer harmonic sources. In IEEE Transactions on Industry Applications. 2015, 2016;52:99-104. https://doi.org/10.1109/TIA.2015.2464175

4. Leite MCC, Vieira FAM, Silva VB, Fortes MZ, Dias DHN. Harmonic analysis of a photovoltaic systems connected to low voltage grid. In IEEE Latin America Transactions. 2018, 2018;16:112-117. https://doi.org/10.1109/TLA.2018.8291462

5. Tang B, Ma S, Lin S, Chen G, Fu Y. Harmonic current emission level assessment of residential loadsbased on impedance-gathering trend. In International Transactions on Electrical Energy Systems. 2017;27(5):1-13. https://doi.org/10.1002/etep.2337

6. Arrillaga, J. and Watson, N. R. (2003) Effects of Harmonic Distortion, in Power System Harmonics, Second Edition, John Wiley \& Sons, Ltd, Chichester, UK https://doi.org/10.1002/0470871229.ch4

7. Baggini, A. and Hanzelka, Z. (2008) Voltage and Current Harmonics, in Handbook of Power Quality (ed A. Baggini), John Wiley \& Sons, Ltd, Chichester, UK. https://doi.org/10.1002/9780470754245.ch7

8. Singh GK. Power system harmonics research: a survey. Eur T Electr Power. 2009;19(2):151-172. https://doi.org/10.1002/etep.201

9. Nassif AB, Yong J, Xu W, Chung CY. Indices for comparative assessment of the harmonic effect of different home appliances. International Transactions on Electrical Energy Systems. 2013;23(5):638-654. https://doi.org/10.1002/etep.1620

10. Das JC. Harmonic Generation Effects Propagation and Control. 1st ed. New York: CRC Press; 2017. ISBN:9781498745468.

11. Pichan M, Karimi M, Simorgh H. Improved low-cost sliding mode control of 4-leginverter for isolated microgrid applications. Int Trans Electr Energ Syst. 2018;28(12):e2642. https://doi.org/10.1002/etep.2642

12. Nibouche M, Bouchhida O, Makhlouf B. Design, analysis and implementation of real-time harmonics elimination: a generalized approach. IET Power Electron. 2014;7(9):2424-2436.

13. Czarnecki, L. S. 2000. “An overview of methods of harmonic suppression in distribution systems.” In Proceedings of the IEEE PES Summer Meeting, 800-5. https://doi.org/10.1109/PESS.2000.867456

14. Singh, B., Jayaprakash, P., and Kothari, D. P. 2010. "Magnetics for neutral current compensation in three-phase four-wire distribution system." In Proceedings of the International Conference on Power Electronics, Drives and Energy Systems, 1-7. https://doi.org/10.1109/ PEDES.2010.5712545.

15. El-Saadany EF, Salama MMA, Chikrani AY. New passive filter design for neutral current cancellation in balanced 3-phase 4-wire nonlinear distribution systems. Eur T Electr Power. 2003;13(2):79-89. https://doi.org/10.1002/etep.4450130203

16. Jou BHL, Wu JC, Wu KD, Chiang WJ, Chen YH. Analysis of zig-Zag transformer applying in the three-phase four-wire distribution power system. IEEE Transactions on Power Delivery. 2005;20(2):1168-1173. https://doi.org/10.1109/TPWRD.2005.844281

17. Czarnecki LS. Harmonic blocking compensator: an alternative for improving power quality. In: In Proceedings 6th International Conference Harmonics Power System; 1994:283-288.

18. Tanaka T, Akagi H. Harmonic power detection based on the pq theory and its applications. Elect Eng Jpn. 1995;115(3):96-107. https://doi. org/10.1002/eej.4391150309

19. Schoene J, Walling R, Bo Y, et al. Analysis and mitigation of excessive zero-sequence harmonic currents in distribution systems. Transmission and Distribution Conference and Exposition (T\&D) IEEE PES. 2012;1-6. https://doi.org/10.1109/TDC.2012.6281508

20. Oliveira JC, Oliveira LCO, Belchior FN, Oliveira RN, Barbosa JA Jr. Frequency domain model for zero-sequence electromagnetic harmonic filter performance analysis. In International Transactions on Electrical Energy Systems. 2014;25(10):1-15. https://doi.org/10.1002/ etep. 1964

21. Oliveira LCO, Oliveira RN, Souza JB, Freitas SCL. Electromagnetic zero-sequence harmonics blocker: modeling and experimental analysis. Journal of Energy and Power Engineering. 2014;8(2014):1425-1431.

22. McLYMAN CWT. Transformer and inductor design handbook. 3rd ed. New York: CRC Press; 2004.

How to cite this article: Freitas SCL, de Oliveira LCO, da Silva Oliveira P, Exposto B, Oliveira Pinto JG, Afonso JL. Modeling, design, and experimental test of a zero-sequence current electromagnetic suppressor. Int Trans Electr Energ Syst. 2020;30:e12222. https://doi.org/10.1002/2050-7038.12222 